\author{
Federal Reserve Bank of Dallas \\ Globalization and Monetary Policy Institute \\ Working Paper No. 246 \\ http://www.dallasfed.org/assets/documents/institute/wpapers/2015/0246.pdf
}

\title{
Testing for a Housing Bubble at the National and Regional Level: The Case of Israel ${ }^{*}$
}

\author{
Itamar Caspi \\ Bar-Ilan University and Bank of Israel
}

August 2015

\begin{abstract}
Between 2008 and 2013, home prices in Israel appreciated by roughly 50 percent in real terms, with increases of nearly 60 percent in some regions. This paper examines whether this phenomenon reflects the presence of a national or regional housing bubble by applying econometric tests for explosive behavior to quality adjusted national and regional level data on the home price to rent ratio, while controlling for various fundamental factors, including interest rates, income and the leverage ratio. Overall, study results indicate that the recent housing price appreciations at the national and regional levels are consistent with the developments of the fundamentals - supply and demand factors that are represented by rent payments and interest rates - and not with a housing bubble scenario. Most of the results are robust to a variety of tests and alternate specifications. The framework I provide to study the Israeli case may be applied to study other housing markets facing similar developments.
\end{abstract}

JEL codes: C22, G12, R21

\footnotetext{
* Itamar Caspi, Research Department, Bank of Israel, P.O. Box 780, Jerusalem 91007, Israel. itamar.caspi@boi.org.il. I thank Yossi Yakhin, Nathan Sussman, Akiva Offenbacher, Sigal Ribon, Offer Lieberman, Jonathan Benchimol, Dana Orfaig, Nadav Steinberg, Lior Gallo, two anonymous referees, as well as the participants at the Bank of Israel's Research Department seminar and the DIW Macroeconometric Workshop for helpful comments and discussions. The views in this paper are those of the author and do not necessarily reflect the views of the Bank of Israel, the Federal Reserve Bank of Dallas or the Federal Reserve System.
} 


\section{Introduction}

Between 2008 and 2013, home prices in Israel increased by 50 percent in real terms, reaching 60 percent in some regions. This increase is the highest among OECD member countries over the same period. Figure 1 (below) provides data on two measures commonly used to gauge home price deviations from fundamentals, the price to rent and price to income ratios, at the national level for the period from January 1999 to July 2013. Both measures significantly deviate from their sample means (horizontal line, in red) at their current levels, and thus suggest a possible distortion in home prices. Despite their intuitive appeal, inferences about housing market conditions based on these measures might be misleading, since the measures do not explicitly account for possible changes in other fundamental factors besides rent and income (Himmelberg et al., 2005).

Figure 1. Measures for Deviations of Home Prices from Fundamentals (January 1999 - July 2013)

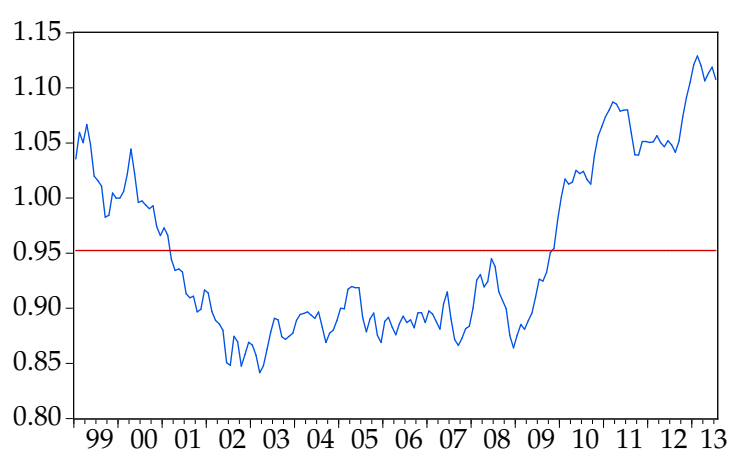

(a) Price to Rent Ratio

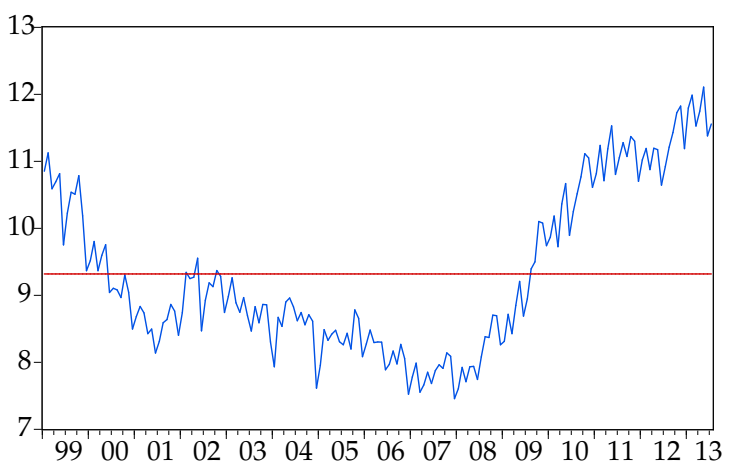

(b) Price to Income Ratio

Notes: Both measures are compared with their sample means (horizontal line, in red). The price to rent ratio is an index normalized to January $2000=1$. Income is measured as the annualized average wage per employee.

Source: CBS, Dovman et al. (2012) and Bank of Israel calculations.

Israel is one of the few advanced economies to be mostly unaffected by the recent global financial crisis of 2007-08. Additionally, there was no buildup of home prices in Israel prior to this crisis. Nonetheless, the recent increase in home prices occurred with an unprecedented and persistent drop in the short term monetary policy rate during 2008. Theoretically, low interest rates should contribute to higher home prices (Poterba, 1984). Yet, some relate prolonged periods of too-low interest rates with the emergence of a housing bubble (e.g., Taylor (2007)). A failure to detect a housing bubble in real time may lead to damaging implications in the aftermath of its burst, such as overbuilding (Glaeser et al., 2008) or financial distress. It also has severe consequences for the real economy, including massive mortgage defaults (e.g., the subprime crisis in the United 
States).

This paper addresses the question of whether recent home price appreciation in Israel reflects the existence of a national or regional housing bubble or whether it is just the result of changes in fundamental supply and demand factors. ${ }^{1}$ To answer this question, I integrate a housing market version of the dynamic Gordon growth model (Campbell et al., 2009), as well as advanced econometric bubble detection and monitoring strategies (Phillips et al., 2011, 2013b; Homm and Breitung, 2012). The dynamic Gordon growth model decomposes changes in the price to rent ratio into changes in the expected paths of rent price growth rates, risk-free rates and risk premiums. A fourth "model consistent" factor that might affect the price to rent ratio is the rational bubble component. The model implies that if a bubble is present, then it must be expected to grow explosively in the sense that it has an autoregressive root greater than unity. Consequently, a price to rent ratio that embodies such an explosive bubble component must inherit its explosiveness. Phillips et al. (2011), Phillips and Yu (2011) and Phillips et al. (2013b) develop powerful test procedures that exploit this feature of explosiveness to identify bubbles. ${ }^{2}$ Furthermore, they and Homm and Breitung (2012) propose methods to carry out real time monitoring for bubbles.

I contribute to the empirical literature in three ways. First, I suggest a straightforward framework for incorporating leverage and mortgage rate elements into the Phillips et al. (2011) and Phillips et al. (2013b) bubble detection frameworks. Second, to the best of my knowledge, this paper is the first one to apply the Phillips et al. (2011) and Phillips et al. (2013b) frameworks to regional data. Conducting regional analysis is important, as it can potentially spot bubbles that exist in one, or several, of the regions and cannot be detected on the national level due to the averaging nature of aggregate national data. This is possible because Israel has readily available quality-adjusted data on home prices and rent at the regional level. Third, this study provides results from a thorough econometric analysis of housing bubbles in a country that is a prime candidate for this type of analysis, because of the recent developments in its housing market.

I use monthly national-level data on the quality-adjusted, price to rent ratio from January 1999 to July 2013. Additionally, I control for macroeconomic fundamental factors by using monthly data on the average wage, as well as the short and long term interest rates on Israeli government bonds and the average mortgage rate set by Israeli banks. I complement the national-level analysis by using regional-level price to rent data for nine regions between the first quarter of 1998 and the second quarter of 2013 to test for the possibility of a regional housing bubble. Using regional-level data accounts

\footnotetext{
${ }^{1}$ This paper does not attempt to answer the question of whether or not there is a problem of affordability, i.e., whether housing prices are too high relative to income.

${ }^{2}$ Diba and Grossman (1988a) were among the first to argue that given a constant discount factor, identifying explosive characteristics in stock prices is equivalent to detecting a bubble.
} 
for the possibility that housing markets in different regions are not fully integrated. ${ }^{3}$

I find that, essentially, recent developments in home prices are inconsistent with a housing bubble scenario. In particular, I cannot reject the null of a no-bubble scenario at the national and regional levels. The majority of the results hold under a variety of tests, alternate specifications, and leverage consideration. One exception is the Gush Dan region for which the results are inconclusive and depend on model specifications. I conclude that, overall, recent price movements in Israel are in line with the development of fundamental factors: mainly, lower interest rates and higher rent prices.

This study relates to the broad empirical literature on housing bubbles. In particular, it relates to a strand of this literature that uses econometric identification schemes based on time series. For example, Arshanapalli and Nelson (2008) apply cointegration tests to examine whether U.S. housing prices and several fundamental factors share a common stochastic trend for first quarter of 2000 through the third quarter of 2007. They find evidence for a bubble. Similarly Taipalus (2006) applies unit root tests to the rent to price ratio for Finland, the United States, the United Kingdom, Spain, and Germany and concludes that, under the assumption that rent growth rates and expected returns are stationary, a bubble existed in nearly all markets. ${ }^{4}$ In this paper I implement an empirical strategy that was recently used by Phillips and Yu (2011) for the US housing market, Yiu et al. (2013) for the Hong Kong local property market, Engsted et al. (2014) for housing markets in OECD countries, and by Pavlidis et al. (2013) to study data from the Dallas FED International House Price Database..$^{5,6}$

This study also relates to studies by Dovman et al. (2012) and Nagar and Segal (2010) that empirically assess recent developments in the Israeli housing market. Dovman et al. (2012) use multiple econometric bubble detection methods and report little evidence for a housing bubble as of August 2010.7 Nagar and Segal (2010) estimate an econometric model of the Israeli housing market using cointegration methods and assert that in 2010, home prices deviated by 8 to 20 percent from their long-run levels.

The remainder of this paper is organized as follows. In Section 2, I present a simple asset pricing model in the context of the housing market. Section 3 gives a technical

\footnotetext{
${ }^{3}$ Regional-level analysis is common in the empirical literature on housing bubbles. For examples see Himmelberg et al. (2005); Case and Shiller (2003); Smith and Smith (2006); Clark and Coggin (2011).

${ }^{4}$ Some other bubble detection strategies, not discussed here, include comparing the annual cost of housing to actual rent (Himmelberg et al., 2005) and a direct derivation of the fundamental price using ex post and projected fundamentals (Smith and Smith, 2006).

${ }^{5}$ The "International House Price Database of the Federal Reserve Bank of Dallas" is documented in Mack and Martínez-García (2011).

${ }^{6}$ Case and Shiller (2003), Smith and Smith (2006), Himmelberg et al. (2005) and McCarthy and Peach (2004) are earlier examples of this strand of literature. These papers focus on the US housing market during the pre-subprime crisis.

${ }^{7}$ Housing bubble indices developed in Dovman et al. (2012) are now updated on a regular basis and used for monitoring purposes by the Bank of Israel.
} 
description of the econometric bubble detection method I use. Section 4 briefly describes the data I use. In Section 5, I present and discuss the results of the tests. Section 6 presents a sensitivity analysis of my results, and Section 7 concludes.

\section{Theoretical Background}

Himmelberg et al. (2005) provide the following definition for a housing bubble: "We think of a housing bubble as being driven by home buyers who are willing to pay inflated prices for houses today because they expect unrealistically high housing appreciation in the future." The "unrealistically high" part refers to house price growth rates that are not related to housing market fundamentals, mainly expected rent payments and discount rates. Though this definition is quite intuitive, it is rather general and needs some more refinement.

In this study, the focus is on bubbles of the rational type, commonly referred to as "rational bubbles". This terminology refers to asset price bubbles that arise in models where all investors have rational expectations. ${ }^{8}$ Though many historical episodes of booms and crashes in asset prices are labelled in retrospect as bubbles (as in the cases of the dot.com bubble in the late 1990s or the more recent the US housing bubble), the existence of bubbles within rational expectations models is still a matter of debate (Brunnermeier, 2008). For instance, bubbles can be ruled out under rather weak assumptions within the framework of competitive general equilibrium models with infinitely lived representative agents (Santos and Woodford, 1997). In contrast, overlapping generations models permit the existence of such bubbles. (One example is Galí, 2014). In general, the theoretical feasibility of rational bubbles largely depends on underlying assumptions about the economy, such as the availability of information, trading constraints, liquidity considerations, etc. ${ }^{9}$

Over the years, applied economists have tried resolving the conflict about the existence of bubbles by formulating econometric procedures designed to test the existence of such rational asset price bubbles. One strand of the literature utilizes predictions from rational asset pricing models to test the consistency of the data with the no-bubble hypothesis. This is generally done by comparing the stochastic properties found in the data with the dynamics implied by the no-bubble condition.

${ }^{8}$ For surveys on other types of bubbles see Brunnermeier (2008), Iraola and Santos (2008) and Scherbina (2013).

${ }^{9}$ Proving the existence of bubbles can also serve as a tool for discriminating between models (Flood and Hodrick, 1990). 


\subsection{The Model}

To gain more insight on the rationale behind these econometric tests for bubbles, I follow Campbell et al. (2009) and present a theoretical home pricing model for the housing market. I first denote the definition of the realized real gross return for holding a home for one period by

$$
V_{t+1}=\frac{P_{t+1}+R_{t+1}}{P_{t}}
$$

where $V_{t}$ denotes the real gross return on a home held from time $t$ to time $t+1, P_{t}$ is the real price of a home and at the end of period $t$, and $R_{t+1}$ is the real payment received for renting the house from time $t$ to $t+1$.

Using the Campbell and Shiller (1988) method we can express the log-linear approximation of Eq. (1) as: ${ }^{10}$

$$
v_{t+1} \approx \kappa+\rho p_{t+1}+(1-\rho) r_{t+1}-p_{t}
$$

where $p_{t} \equiv \log \left(P_{t}\right), r_{t} \equiv \log \left(R_{t}\right), v_{t} \equiv \log \left(V_{t}\right), \rho=1 /\left[1+e^{(\overline{r-p})}\right], \overline{r-p}$ is the sample mean of the $\log$ rent to price ratio, and

$$
\kappa=-\log (\rho)-(1-\rho) \log \left(\frac{1}{\rho}-1\right) .
$$

Solving Eq. (2) for the log price to rent ratio by forward iterations results in the following dynamic log-linear approximation of the present value formula:

$$
p_{t}-r_{t}=\frac{\kappa}{1-\rho}+\sum_{j=0}^{\infty} \rho^{j}\left(\Delta r_{t+1+j}-v_{t+1+j}\right)+\lim _{j \rightarrow \infty} \rho^{j}\left(p_{t+j}-r_{t+j}\right) .
$$

I further assume that the single period return on a home is composed of the real risk-free rate, $i_{t}$, and a risk premium, $\varphi_{t}$, such that $v_{t}=i_{t}+\varphi_{t} \cdot{ }^{11}$ Thus, Eq. (3) can be rewritten as

$$
p_{t}-r_{t}=\frac{\kappa}{1-\rho}+\sum_{j=0}^{\infty} \rho^{j}\left(\Delta r_{t+1+j}-i_{t+1+j}-\varphi_{t+1+j}\right)+\lim _{j \rightarrow \infty} \rho^{j}\left(p_{t+j}-r_{t+j}\right) .
$$

Eq. (4) holds ex post (since it follows from an identity). Hence, it must hold ex ante in expectations, conditioned on the information set available at time $t$. Thus, we can take conditional expectations and relate the current price to rent ratio to expected rent

\footnotetext{
${ }^{10}$ For a discussion of the approximation's accuracy, see Appendix A

${ }^{11}$ For simplicity of exposition, I choose to ignore other variables that might also be included in $v_{t}$, such as depreciation, maintenance, property and transaction taxes, the mortgage rate, leverage etc.
} 
growth rates, risk-free rates and risk premiums.

$$
p_{t}-r_{t}=\frac{\kappa-\varphi}{1-\rho}+\mathbb{E}_{t} \sum_{j=0}^{\infty} \rho^{j}\left(\Delta r_{t+1+j}-i_{t+1+j}\right)+\mathbb{E}_{t} \lim _{j \rightarrow \infty} \rho^{j}\left(p_{t+j}-r_{t+j}\right)
$$

where $\mathbb{E}_{t}$ is the expectation operator, and where I've assumed a constant expected risk premium, i.e., that $\mathbb{E}_{t}\left(\varphi_{t+1}\right)=\varphi \cdot{ }^{12,13}$

According to Eq. (3), home prices today are high relative to rent if investors expect some combination of high rent growth rates and low interest rates, or, investors expect prices to rise at a faster rate than rent forever. The latter case is commonly referred to as a rational bubble.

Eq. (5) can be decomposed into two components,

$$
p_{t}-r_{t}=f_{t}+b_{t}
$$

The first component in the right-hand side of Eq. (6), $f_{t}$, is the fundamental component, given by

$$
f_{t}=\frac{\kappa-\varphi}{1-\rho}+\sum_{j=0}^{\infty} \rho^{j} \mathbb{E}_{t}\left(\Delta r_{t+1+j}-i_{t+1+j}\right),
$$

which is stated only in terms of the fundamental factors-the risk premium and the expected paths of rent growth rates and risk-free rates. This relation commonly referred to as the Gordon growth model (Campbell and Shiller, 1988).

The second component in the right-hand side of Eq. (6), $b_{t}$, is the rational bubble, given by

$$
b_{t}=\mathbb{E}_{t} \lim _{j \rightarrow \infty} \rho^{j}\left(p_{t+j}-r_{t+j}\right) .
$$

If the transversality condition, $\lim _{j \rightarrow \infty} \rho^{j}\left(p_{t+j}-r_{t+j}\right)=0$, holds, the log price to rent ratio does not explode. ${ }^{14}$ That is, no bubble exists and the observed ratio equals the fundamentally implied ratio. In contrast, the existence of a bubble component is a situation where the price to rent ratio exceeds what is implied by fundamentals. The latter case is consistent with investors who expect to be compensated for overpayment by the expected appreciation of the bubble component. That is, investors buy homes since they expect to sell them for a higher price in the future. In essence, this behavior describes the general notion of a bubble quite intuitively.

\footnotetext{
${ }^{12}$ The assumption of constant expected risk premiums (or discount factors) is common in the literature on testing for rational bubbles (Gürkaynak, 2008). Nonetheless, relaxing this assumption need not change the main conclusions as long as we rule out explosive risk premiums.

${ }^{13}$ Campbell et al. (2009) assume a time varying risk premium.

${ }^{14}$ Campbell et al. (2009) assume in their model that no bubbles are present.
} 
The presence of such a component is consistent with the rational expectations hypothesis, hence the term, "rational" bubble. In fact, adding any process that satisfies the following explosive (sub-martingale) property

$$
\mathbb{E}_{t}\left(b_{t+1}\right)=\rho^{-1} b_{t}=\left[1+e^{(\overline{r-p})}\right] b_{t}
$$

to $f_{t}$ solves Eq. (2). ${ }^{15,16}$

The condition given in Eq. (9) implies that in the presence of a bubble component, $p_{t}-r_{t}$ will manifest explosive autoregressive behavior. This is because the explosiveness property of the bubble component sooner or later will dominate the stochastic properties of $\Delta r_{t}$ and $i_{t}$, regardless of whether they are stationary or integrated of order one. Hence, under the assumption of a constant expected risk premium, testing for a rational housing bubble in this model is equivalent to testing whether $p_{t}-r_{t}$ has a root greater than one, while verifying that neither $\Delta r_{t}$ nor $i_{t}$ have explosive roots.

Nonetheless, we cannot rule out other possible combinations of stochastic properties that may exist. For example, if evidence for explosiveness is found in $p_{t}-r_{t}$ and in either one of the fundamental factors, no conclusive inference on the existence of a bubble in $p_{t}-r_{t}$ can be made. Alternatively, finding that one of the fundamental factors is explosive while the same does not apply to $p_{t}-r_{t}$, may be interpreted as evidence against the underlying model.

\subsection{Implications for Econometric Tests for Bubbles}

Several rational bubble detection strategies were developed over the past three decades based on insights arising from variations of the model described above. ${ }^{17}$ Diba and Grossman (1988a) were among the first to suggest testing for bubbles by using unit root and cointegration tests on stock prices and dividends. ${ }^{18}$ They find that stock prices and dividends are integrated of the same order (one) and that they are cointegrated. Based on these results, Diba and Grossman conclude that the no-bubble hypothesis cannot be rejected for US stock prices. Evans (1991) criticized the work of Diba and Grossman and the use of unit root and cointegration tests due to their power loss in the presence of a

\footnotetext{
${ }^{15}$ The explosiveness property of $b_{t}$ comes from the fact that $1+e^{(\overline{r-p})}>1$. Hence, when $b_{t} \neq 0$, the log bubble component grows at rate $g$ in expectations, where $g=e^{(\overline{r-p})}>0$.

${ }^{16}$ Diba and Grossman (1988a) point out another implication of the model, namely, that $b_{t}$ can be either zero at all times or positive at all times. To see why, note that a negative value of $b_{t}$ today implies that investors expect a future price of zero. Given free disposal, a negative bubble can be ruled out. Yet, a bubble cannot emerge at some point in the future since this necessarily implies that the forecast error of the bubble component is not zero in expectations, thus violating Eq. (9).

${ }^{17}$ See Flood and Hodrick (1990) for an early survey of the literature and Gürkaynak (2008) for an updated survey of econometric tests for bubbles.

${ }^{18}$ Other examples for bubble test methods include the variance bounds test (LeRoy and Porter, 1981; Shiller, 1981), West's two-step tests (West, 1987) and the intrinsic bubbles test (Froot and Obstfeld, 1992).
} 
periodically collapsing bubble, i.e., a bubble that repeatedly emerges and bursts (but remains at positive levels at all times). Intuitively, this power loss phenomenon comes from the fact that a time series containing a complete cycle of a bubble tends to appear more like a stationary series rather than a unit root, due to the apparent 'mean-reversion' caused by the tendency of the bubble to burst after the preceding run-up stage. This in turn biases unit root tests toward rejection of the null.

More recently, Phillips, Wu, and Yu (2011, hereinafter PWY) show how to overcome the low power problem in the presence of a periodically collapsing bubble. PWY's method is based on using recursive right-tail unit root tests where the null of a unit root is tested against the alternative of a mildly explosive process. ${ }^{19}$ In this case, the null hypothesis is of no-bubble and a rejection of this null is interpreted as evidence for a bubble. ${ }^{20} \mathrm{PWY}^{\prime}$ s method is also designed to consistently estimate the origination and termination dates of a bubble (if it exists). This date stamping feature can also be used as a real time monitoring device. ${ }^{21}$ Homm and Breitung (2012) compare PWY's method to other common bubble detection methods and find, using Monte Carlo simulations, that it indeed has increased power in the detection of periodically collapsing bubbles and that it performs relatively well as a real time monitoring device.

Before continuing, a comment is warranted. Econometric tests for rational bubbles, including PWY's method, usually formulate the null hypothesis as 'no-bubble'. Thus, rejection of the null might lead one to conclude that a bubble is present in the data. Unfortunately, all that these bubble tests can show us is whether the data we observe are inconsistent with the null, since rejection is only possible within a specified model. ${ }^{22}$

\section{Econometric Methodology}

Implementing PWY's test for bubbles is quite straightforward. The procedure involves recursive estimates of the Dickey and Fuller (1979) $\tau$-statistic, where the basic empirical specification used is the following standard Augmented Dickey-Fuller (ADF) auxiliary regression:

$$
y_{t}=\mu+\delta y_{t-1}+\sum_{i=1}^{k} \phi_{i} \Delta y_{t-i}+\varepsilon_{t}, \quad \varepsilon_{t} \sim i i d\left(0, \sigma^{2}\right)
$$

where $y_{t}$ is the time tested for explosiveness, $\mu$ is the intercept, $\delta$ is the autoregressive coefficient, $k$ is the maximum number of lags, $\Delta$ is the difference operator, $\phi_{i}$ for $i=$

\footnotetext{
${ }^{19}$ Phillips, Shi, and Yu (2013b) generalize the PWY procedure such that it is possible to test for multiple bubbles in long time series.

${ }^{20}$ The asymptotic theory of mildly explosive processes is developed in Phillips and Magdalinos (2007).

${ }^{21}$ Large sample properties of the bubble date-stamping procedure are developed in Phillips and $\mathrm{Yu}(2009)$.

${ }^{22}$ Hamilton (1986) argues that the interpretation of the results of econometric tests for speculative price bubbles depends on the nature of any nonstationarity in the fundamentals.
} 
$1 \ldots k$ are the coefficients of the lagged first difference and $\varepsilon_{t}$ is an iid error term.

Traditionally, Eq. (10) is used to test the null of a unit root against the alternative of stationarity. Nonetheless, the same equation can be used to carry out a test for a mildly explosive root. ${ }^{23}$ Formally we test for:

$$
\begin{array}{lll}
H_{0}: & \delta=1 & \text { (no-bubble) } \\
H_{1}: & \delta>1 & \text { (bubble) }
\end{array}
$$

using the ADF statistic, defined as

$$
\operatorname{ADF}=\frac{\hat{\delta}}{\operatorname{SE}(\hat{\delta})}
$$

where $\hat{\delta}$ is the OLS estimate of $\delta$ and SE stands for 'standard error'.

Before proceeding to a more detailed description of PWY's testing procedure, some notation is required. First, assume a sample interval of $[0,1] .{ }^{24} \mathrm{Next}$, denote by $\delta_{r_{2}}^{r_{1}}$ and by $\mathrm{ADF}_{r_{2}}^{r_{1}}$ the autoregressive coefficient from Eq. (10) and its corresponding ADF statistic, respectively, when both are estimated over the (normalized) sample $\left[r_{1}, r_{2}\right]$, where $r_{1}$ and $r_{2}$ are fractions of the sample such that $0<r_{1}<r_{2}<1$. Finally, denote by $r_{w}$ the (fractional) window size of the regression, defined by $r_{w}=r_{2}-r_{1}$ and $r_{0}$ as the fixed initial window, set by the user.

The supremum ADF (SADF) test proposed by PWY is based on recursive calculations of the ADF statistics with an expanding window. The estimation procedure proceeds as follows (see Figure 2): First, we set the first observation of the sample as the starting point of the estimation window, i.e., $r_{1}=0$. In the next step, we set the end point of the initial estimation window, $r_{2}$, according to a choice of a minimal window size, $r_{0}$, such that the initial window size is defined as $r_{w}=r_{2}-r_{1}=r_{2}$. Finally, we recursively estimate $\delta_{r_{2}}^{0}$ using Eq. (10) and calculate its corresponding $\mathrm{ADF}_{r_{2}}^{0}$ statistic, incrementing the window size, $r_{2} \in\left[r_{0}, 1\right]$, one observation at a time. In the final step, estimation is based on the whole sample (i.e., $r_{2}=1$ and the $\mathrm{ADF}$ statistic is $\mathrm{ADF}_{1}^{0}$ ). The SADF statistic, as defined by PWY, is the supremum value of the $\mathrm{ADF}_{r_{2}}^{0}$ sequence for $r_{2} \in\left[r_{0}, 1\right]$ :

$$
\operatorname{SADF}\left(r_{0}\right)=\sup _{r_{2} \in\left[r_{0}, 1\right]}\left\{\operatorname{ADF}_{r_{2}}^{0}\right\}
$$

\footnotetext{
${ }^{23}$ Phillips and Magdalinos (2007) define a mildly explosive root using the following data generating process

$$
y_{t}=\delta_{n} y_{t-1}+\varepsilon_{t},
$$

where $\delta_{n}=1+\frac{c}{k_{n}}$, and where $\left(k_{n}\right)_{n \in \mathbb{N}}$ is a sequence increasing to $\infty$ such that $k_{n}=o(n)$ as $n \rightarrow \infty$. ${ }^{24}$ We can think of this sample as a standardized version of true sample (i.e., divided by $T$ ).
} 
The distribution of the SADF statistic under the null hypothesis has a nonstandard form. Asymptotic and finite sample critical values are obtained by Monte Carlo simulation methods. Accordingly, if the SADF statistic is larger than the corresponding critical value, we reject the null hypothesis of a unit root in $y_{t}$ in favor of a mildly explosive process.

Figure 2. Illustration of the SADF Test Procedure

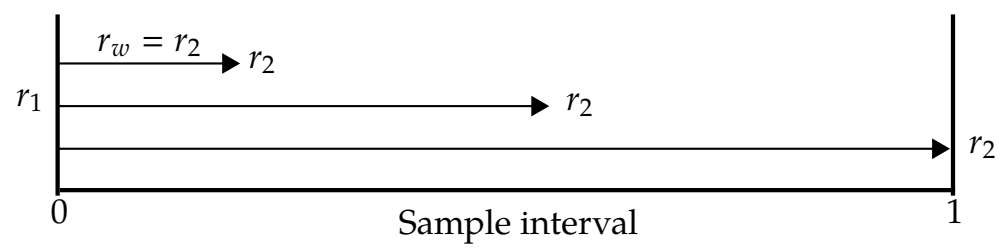

Notes: Set $r_{1}=0$ and $r_{2} \in\left[r_{0}, 1\right]$. Next, use $\left[0, r_{2}\right]$ as the initial window and vary $r_{2}$. At each step, $r_{w}=r_{2}$ is the window width.

\subsection{Date-stamping Bubble Periods and Monitoring}

As mentioned in the previous section, the PWY procedure can also be used to consistently estimate the origination and termination dates of a bubble. Thus, if the null hypothesis of no-bubble is rejected, we can, under general regularity conditions, consistently estimate the bubble period (Phillips and Yu, 2009). Moreover, Homm and Breitung (2012) and Phillips et al. (2013b) show that these date-stamping procedures can be used not only as an ex post dating strategy but also for real time monitoring of bubbles.

The date-stamping procedure is based on comparing each element of the $\mathrm{ADF}_{r_{2}}^{0}$ sequence to its corresponding right-tailed critical value which is based on a sample size of $T r_{2}$ observations. ${ }^{25}$ The estimated origination point of a bubble, denoted by $r_{e}$, is the first chronological observation in which $\mathrm{ADF}_{r_{2}}^{0}$ crosses its corresponding critical value from below. The estimated termination point, denoted by $r_{f}$, is the first chronological observation which comes after $r_{e}$ in which the $\mathrm{ADF}_{r_{2}}^{0}$ crosses its critical value from above. Formally, the estimates of the bubble period are given by

$$
\begin{aligned}
& \hat{r}_{e}=\inf _{r_{2} \in\left[r_{0}, 1\right]}\left\{r_{2}: \mathrm{ADF}_{r_{2}}^{0}>c v_{r_{2}}^{\beta_{T}}\right\} \\
& \hat{r}_{f}=\inf _{r_{2} \in\left[\hat{r}_{e}, 1\right]}\left\{r_{2}: \mathrm{ADF}_{r_{2}}^{0}<c v_{r_{2}}^{\beta_{T}}\right\}
\end{aligned}
$$

where $c v_{r_{2}}^{\beta_{T}}$ is the $100\left(1-\beta_{T}\right) \%$ critical value of the standard ADF statistic based on

${ }^{25}$ For a detailed presentation of the date stamping procedure, see Phillips et al. (2011) and Phillips and Yu (2011). 
$\left[\mathrm{Tr}_{2}\right]$ observations. ${ }^{26,27}$

Another procedure used for monitoring purposes is the CUSUM test suggested by Homm and Breitung (2012). This test is designed to detect a regime shift between a unit root process and an explosive root process in real time. Let $t_{0}=\left\lfloor T r_{0}\right\rfloor$ be the training sample and let $\left[t_{0}+1, t_{2}\right]$ be the monitoring interval, where $t_{2}=\left\lfloor T r_{2}\right\rfloor$ is the latest observation of the monitoring interval. The CUSUM statistic is defined as

$$
\operatorname{CUSUM}_{t_{0}}^{t_{2}}=\frac{1}{\hat{\sigma}_{t_{0}}^{2}} \sum_{j=t_{0}+1}^{t_{2}} \Delta y_{j}=\frac{1}{\hat{\sigma}_{t_{0}}^{2}}\left(y_{t_{2}}-y_{t_{0}}\right)
$$

where $\hat{\sigma}_{t_{0}}^{2}$ is a consistent estimate of the variance of $\Delta y_{t}$ over the sample $\left[1, t_{0}\right]$. Accordingly, detection of a shift toward a bubble regime is made when the CUSUM statistic crosses its critical values sequence (at some predefined significance level) from below.

\subsection{Indirect Inference and Confidence Intervals}

Statistical inference on the Least Squares (LS) estimate of $\delta$ suffers from two drawbacks. First, under the mildly explosive alternative we cannot use the standard confidence intervals. Instead, as shown by (Phillips and Magdalinos, 2007), a correct $100(1-\alpha) \%$ confidence interval for the LS estimator of $\hat{\delta}_{n}$ is given by

$$
\left[\hat{\delta}_{n}-\frac{\left(\hat{\delta}_{n}\right)^{2}-1}{\left(\hat{\delta}_{n}\right)^{n}} C_{\alpha}, \hat{\delta}_{n}+\frac{\left(\hat{\delta}_{n}\right)^{2}-1}{\left(\hat{\delta}_{n}\right)^{n}} C_{\alpha}\right],
$$

where $C_{\alpha}$ is the two-tailed percentile critical value of the standard Cauchy distribution. ${ }^{28}$

The second drawback comes from the fact that the LS estimate of $\delta$ is known to be biased downward in finite samples. Hence, using the confidence intervals shown above with the LS point estimate of $\delta$ might be misleading. ${ }^{29}$ Phillips et al. (2011) show how to correct the bias by applying the indirect inference method. Accordingly, $H$ paths of an $\mathrm{AR}(1)$ process for $y_{t}$ are simulated for different values of $\delta \in \Phi$, where $\delta$ is the autoregressive coefficient and $\Phi$ is the parameter space. Let $\hat{\delta}_{h}^{L S}(\delta)$ denote the LS estimator of $\delta$, given a path $h$, where $h=1, \ldots, H$ and let $\bar{\delta}^{L S}(\delta)$ be the mean of $\hat{\delta}_{h}^{L S}(\delta)$

\footnotetext{
${ }^{26}$ In order to get a consistent test procedure that asymptotically eliminate type $I$ errors there is a need to let $\beta_{T} \rightarrow 0$ as $T \rightarrow 0$. However in applied work it is convenient to use a constant $\beta_{T}$ such as $5 \%$ (see Phillips et al. (2013b)).

27Phillips and $\mathrm{Yu}$ (2011) argue that the date stamping procedure requires that the duration of the bubble to be non-negligible. In Phillips et al. (2013b) the authors define $\log (T) / T$ as a minimal lasting time (in fractional terms of the sample) for a bubble period.

${ }^{28}$ The critical values for $90 \%, 95 \%$ and $99 \%$ are $6.315,12.7$ and 63.66 , correspondingly.

${ }^{29}$ The problem of a biased estimate also holds when the true data are generated with $\delta \leq 1$.
} 
over $h$, i.e.,

$$
\bar{\delta}_{H}^{L S}(\delta)=\frac{1}{H} \sum_{h=1}^{H} \hat{\delta}_{h}^{L S}(\delta) .
$$

The indirect estimator, $\tilde{\delta}_{H}$, is defined as

$$
\tilde{\delta}_{H}=\underset{\delta \in \Phi}{\operatorname{argmin}}\left\|\hat{\delta}^{L S}-\bar{\delta}_{H}^{L S}(\delta)\right\|,
$$

where $\|\cdot\|$ is some finite dimensional distance metric and $\hat{\delta}^{L S}$ is the LS estimate of $\delta$ from the actual data.

\section{Data}

The data on home and rent prices are taken from the Israeli Central Bureau of Statistics (CBS). I use seasonally unadjusted monthly observations on the price to rent ratio at the national level, composed of the Prices of Dwellings Index (hereinafter: the home prices index) and on the Owner Occupied Dwellings Services Price Index (hereinafter: the rent index). ${ }^{30}$ I use data on the one-year real risk-free rate, measured by the difference between the Bank of Israel (BOI) nominal interest rate (for one year) and one-year expected inflation, both obtained from the Bank of Israel. The latter is measured by the yield spread between inflation-adjusted and nominal Israeli government bonds with one year maturity. ${ }^{31,32}$. The sample I use covers the period from January 1999 to July 2013 and includes 175 observations. The choice of this specific sample is due to the availability of data. For further details on the data, see Appendix C.

Table 1 presents summary statistics for the log price to rent index (denoted as $p_{t}-r_{t}$ ), log real rent index $\left(r_{t}\right.$, deflated by the CPI) and the short-term real risk-free rate $\left(i_{t}\right)$. Several notable observations arise from the table. First, the price to rent ratio reached a peak in February 2013. The latest observation available (July 2013) is around 2\% lower than the peak. Second, the real risk-free rate reached a record low of $-1.9 \%$ in the midst of the recent global financial crisis (June 2009), due to the drop in the Bank of Israel interest rate (notwithstanding the drop in expected inflation.) Third, real rent is at its peak at the end of the sample, reflecting a 20\% increase since July 2008. And finally, all series possess a high degree of persistence, even at the 12th lag (see the last three columns of Table 1). This high degree of autocorrelation is evident in the apparent nonstationary nature of these series.

\footnotetext{
${ }^{30}$ The latter is included in the CPI while the former is not.

${ }^{31}$ Expected inflation here is similar to the notion of the 'TIPS Spread' in the US.

${ }^{32}$ Alternatively, I used the yield on 1-year CPI-indexed government bonds (zero coupon bonds). Results are similar (not presented).
} 
Table 1. Summary Statistics (1999:M1 - 2013:M7)

\begin{tabular}{llllllll}
\hline & & & & & \multicolumn{3}{c}{ Autocorrelation $^{\mathrm{a}}$} \\
\cline { 5 - 8 } Series & Obs. & Freq. & Min Date & Max Date & $\rho_{1}$ & $\rho_{4}$ & $\rho_{12}$ \\
\hline Log price to rent ratio $p_{t}-r_{t}$ & 175 & Monthly & 2003:M3 & 2013:M2 & 0.97 & 0.87 & 0.66 \\
Log real rent $r_{t}$ & 175 & Monthly & 2008:M6 & 2013:M7 & 0.97 & 0.85 & 0.58 \\
Log gross risk-free real rate $i_{t}$ & 175 & Monthly & 2009:M6 & 2000:M1 & 0.96 & 0.84 & 0.63 \\
\hline
\end{tabular}

a The subscripts for the autocorrelation coefficients $\rho$ indicate the lag order.

Figures 3a-c depict the developments in real home price, real rent and the price to rent ratio over the sample period (all presented in natural logarithms). The motivation behind this study is based on the steep rise seen in the home prices index circa 2008 (see Figure 3a). ${ }^{33}$ Home prices increased during $2008-2013$ by approximately $50 \%$ in real terms, averaging an annual growth rate of nearly $10 \%$. However, prior to the recent run-up, there was a continuous period of real price depreciation. Though not presented in this figure, this real depreciation lasted for more than a decade. Despite following an upward trend since 2008, the rent index does not show the same rapid expansion pattern as prices. The short-term risk-free rate is depicted in Figure $3 \mathrm{~d}$. The series appear to follow a downward sloping trend as of the beginning of the 2000s. This trend is most likely the result of the disinflation process undergone by the Israeli economy following the stabilization program of $1985 .{ }^{34}$ Arguably, the most important feature in the context of the recent developments in home prices is the big decline of the risk-free rate seen right after the outbreak of the global financial crisis.

For the regional-level analysis I use quarterly data on the mean home prices and rent (the latter is transformed into annual terms) sorted by nine regions and given in current shekel prices (I use seasonally unadjusted data.) The regional data's sample covers the period from 1998:Q1 to 2013:Q2 and includes 62 quarterly observations. (See Appendix $C$ for further details.) In this study I focus on the 3.5-4 room apartments segment. I do so since quality adjusted-data (such as a regional hedonic price indexes) are not available. I argue that using this specific segment roughly controls for quality. Moreover, the 3.5-4 room apartments segment represents the median apartment (out of the stock) in Israel, and also constitutes the vast majority of transactions.

The nine regional log price to rent ratios are plotted in Figure 4. As we can see from the graphs, the price to rent ratio in all nine regions is currently high compared to historical levels, where the upward trend for most regions started somewhere during the mid to late 2000s. However, the dynamics of the regional price to rent ratios in the last five years are quite heterogeneous. Some of the regions-namely, Center, Gush-Dan,

\footnotetext{
${ }^{33}$ For recent surveys on developments in the Israeli housing market see Dovman et al. (2012) and Nagar and Segal (2010).

${ }^{34}$ For further background on the Israeli stabilization program, see Ben Basat (2002) and Liviatan (2003).
} 
Figure 3. National Level Time Series Plots (1999:M1 - 2013:M7)

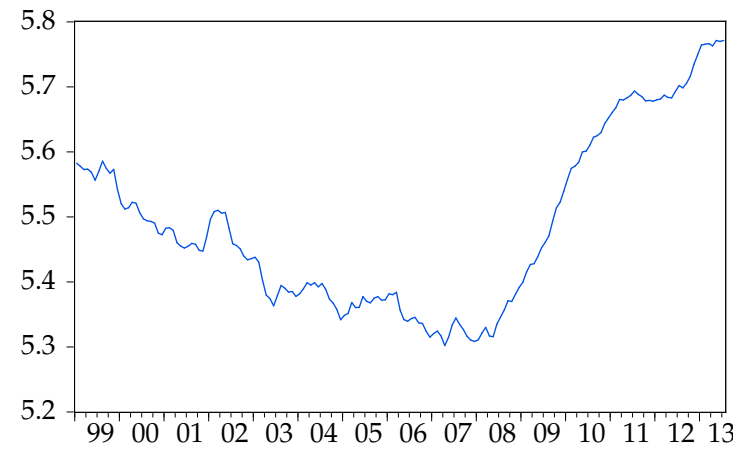

(a) Log real price $p_{t}$

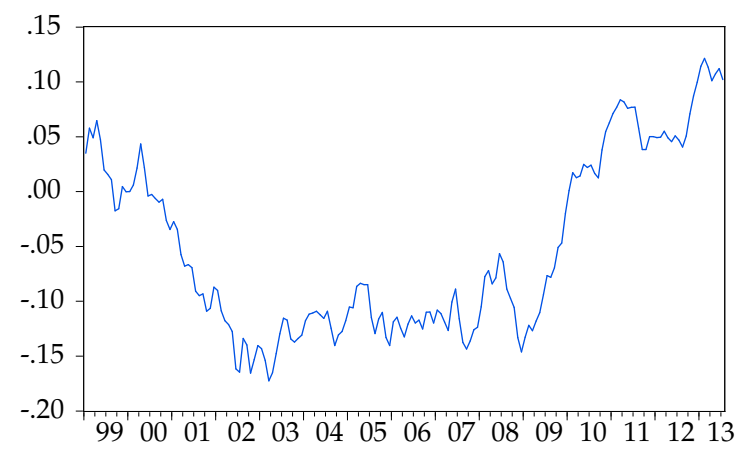

(c) Log price to rent ratio $p_{t}-r_{t}$

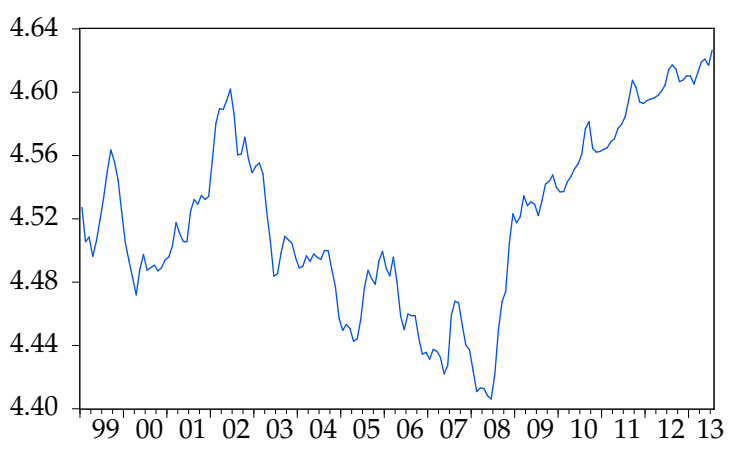

(b) Log real rent $r_{t}$

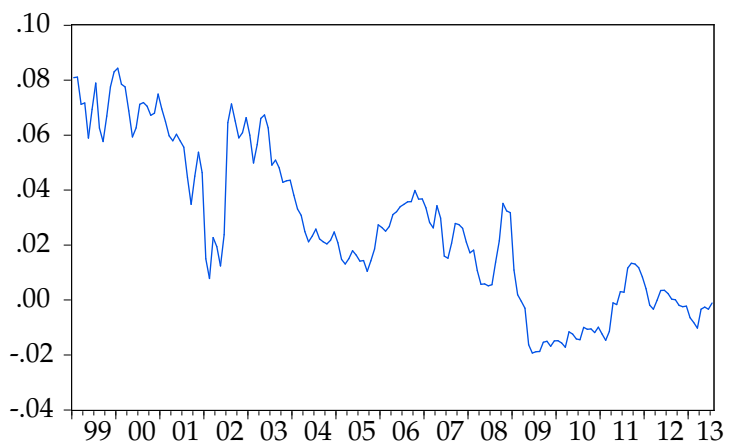

(d) Log gross real risk-free rate $i_{t}$

Notes: $\log$ home prices $\left(p_{t}\right)$ and log rent $\left(r_{t}\right)$ indices are deflated by the CPI. Log price to rent ratio $\left(p_{t}-r_{t}\right)$ is an index, normalized to January $2000=0$. The real risk-free rate is the difference between the Bank of Israel interest rate and expected inflation (see Appendix $C$ for further details).

Haifa and North-exhibit the same pattern seen at the national level, i.e., a rapid rise in the ratio, while the other regions display a rather stable growth path during the same period. The presence of heterogeneous dynamic patterns highlights the importance of regional-level analysis since it potentially enables us to detect regional housing bubbles that otherwise would have been missed within a national level analysis because of the averaging nature of the aggregate ratio. ${ }^{35}$

\section{Results}

\subsection{National Level}

Before I provide a description of the main findings at the national level, I briefly discuss the specifications used for deriving these results. The SADF statistic and critical values are calculated for the log price to rent ratio, log real rent and log gross real risk-free rate

\footnotetext{
${ }^{35}$ For example, testing for a bubble in the stock market during the early 2000s using some general stock price index might miss the presence of a bubble, since the "dot.com" bubble was largely confined to the technology sector. The NASDAQ Composite Index would be more appropriate in this case.
} 
Figure 4. Log Price to Rent at the Regional Level (1998:Q1-2013:Q2)
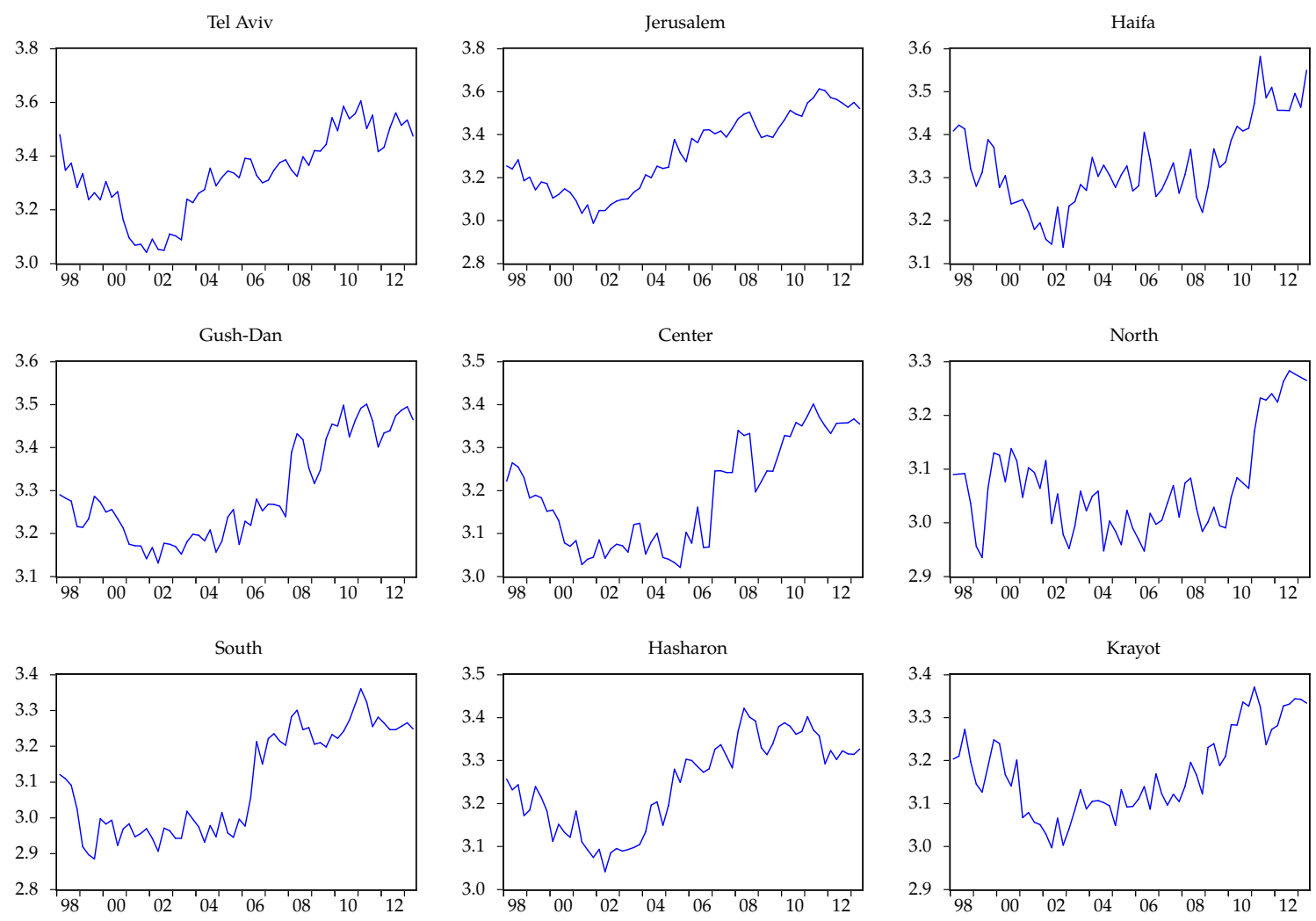

Notes: The data on prices and rent used for constructing the price to rent ratio for each region are for 3.5-4 room apartments within each specific region.

by recursive estimations of Eq. (10) for each individual variable. The conduct of all these tests and critical values simulations are performed using the 'rtadf' EViews Add-in (Caspi, 2013) and Matlab. The optimal lag length is chosen by the Schwartz Information Criterion (SIC) when estimating Eq. (10) for the whole sample (with the maximum number of lags set to 12.) Accordingly, the lag length in the recursive procedure is set to 3 for the $\log$ ratio and for log real rent, and to 2 for the log gross rate. ${ }^{36,37}$ The SADF statistic is recursively estimated with an initial widow size of 36 observations, i.e., 3 years, which constitutes $20 \%$ of the sample. This choice of initial window size relies on Phillips et al. (2011) and Phillips et al. (2013b) who use a window size of approximately 3 years for monthly data. Though my choice of minimal window size is arbitrary and not data driven, my results nonetheless are shown to be robust to different choices of window sizes and lags. (See Section 6.1.) In deriving the critical values for the SADF statistic, I set the data generating process (DGP) for the null to a random walk without

\footnotetext{
${ }^{36}$ Based on Monte Carlo simulations, Phillips et al. (2013b) argue that the SIC provides satisfactory sizes for the SADF test.

${ }^{37}$ Adding lags is highly relevant when making use of the home prices index since it is constructed as a smoothed index which makes it serially correlated by construction. (The home prices index reported by the CBS is a two-month moving average.)
} 
a drift as in Phillips et al. (2011). ${ }^{38}$

Table 2 presents the standard ADF statistic and the SADF statistic for all variables, as well as their corresponding right-tail critical values for the sample of 1999:M1-2013:M7. The table also shows the date where the $\mathrm{ADF}_{0}^{r_{2}}$ sequence has reached its maximum (i.e., the date which corresponds to the SADF statistic.) The ADF statistic is estimated over the whole sample and is mostly used for comparison reasons and not for inference on bubbles. As we can see, according to the SADF test statistic, the null of no-bubble in the log price to rent ratio cannot be rejected at conventional significance levels - the SADF statistic is well below the $90 \%$ critical value of 0.592 needed to reject the null. Furthermore, the same null cannot be rejected for both of the fundamental factors - log rent and the risk-free rate. The SADF statistics valued at -1.495 for $r_{t}$ and 0.983 for $i_{t}$ are also well below their corresponding $90 \%$ critical values. ${ }^{39}, 40$

Table 2. Results of the ADF and SADF Tests

\begin{tabular}{|c|c|c|c|}
\hline & (1) & (2) & (3) \\
\hline eries & $\mathrm{ADF}$ & $\underset{\left(r_{0}=36\right)}{\operatorname{SADF}}$ & Maximum date \\
\hline og price to rent ratio $p_{t}-r_{t}$ & -1.286 & -0.237 & 2002:M6 \\
\hline og rent $r_{t}$ & -1.495 & -0.780 & 2002:M6 \\
\hline og gross real risk-free rate $i_{t}$ & -1.811 & 0.983 & 2002:M4 \\
\hline & \multicolumn{2}{|c|}{ Critical values } & \\
\hline $9 \%$ & 0.592 & 1.891 & \\
\hline $5 \%$ & -0.090 & 1.262 & \\
\hline $0 \%$ & -0.425 & 0.978 & \\
\hline
\end{tabular}

Notes: The table reports the estimated ADF and SADF statistics and the date where the $\mathrm{ADF}_{0}^{r_{2}}$ sequence has reached its maximum for the sample 1999:M1-2013:M7. The initial window size is set to 36 months. The unit root test equations include 3 lags for the log ratio and log real rent, and 6 lags for the log risk-free rate. Critical values for all statistics are derived using Monte Carlo simulation with 10,000 replications where the underlying data are generated by a random walk with normal iid errors.

The SADF statistics of the log price to rent ratio differ from the ADF statistic estimated using the whole sample. That is, the latest value of the $\mathrm{ADF}_{r_{2}}^{0}$ sequence (July 2013) is not the maximal value of the sequence. Accordingly, the $\mathrm{ADF}_{r_{2}}^{0}$ statistic, valued at -0.237 , corresponds to the sample that ends at 2002:M6. The point estimate of the autoregressive

\footnotetext{
${ }^{38}$ In a more recent paper, Phillips et al. (2013a) suggest adding an asymptotically negligible drift to the data generating process of the null as means of increasing the size and power of the test. Adding this drift term does not change my main conclusions. (Not presented, available on demand.)

${ }^{39}$ Though it is possible to apply tests for explosive behavior to any variable, I note that in general, one can rule out explosive behavior in fundamentals ( $\Delta r_{t}$ and $i_{t}$ in our case) based on theoretical grounds. This stems from the notion that no plausible economic model gives rise to an equilibrium in which fundamental factors exhibit explosive patterns.

${ }^{40}$ Interestingly, the null of no-bubble in the risk-free rate is close to rejection at the $90 \%$ level. However, closer inspection reveals that the probable cause of the rejection is the sudden drop of $200 \mathrm{bp}$ in the Bank of Israel policy rate on January 2002. The SADF test is close to mistakenly identifying this period as bubble.
} 
coefficient for the sample 1999:M1-2013:M2 is 0.987 and the (bias adjusted) indirect inference estimator is 1.009 where its $95 \%$ confidence interval, calculated according to Eq. (16), lies between 1.057 and 0.962. ${ }^{41}$ This result is in accordance with the results of the SADF test, namely the non-rejection of the null of unit root (no-bubble.) ${ }^{42}$

Figure 5 plots the sequence of $\mathrm{ADF}_{r_{2}}^{0}$ statistics (solid, blue) together with its corresponding sequence of critical values (dotted, red). As we can see, despite not being currently at its peak, the $\mathrm{ADF}_{r_{2}}^{0}$ is relatively high compared to its historical level. In addition, we see that the test statistics sequence for the price to rent ratio has recently gotten 'closer' to the 95\% critical value threshold. Hence, although we are unable to reject the null of no-bubble, we do see an upward rising trend towards this threshold ever since late 2009. This highlights the importance of the real-time monitoring aspects of the PWY strategy. Crossing the rejection threshold at some point in the future may serve as an early warning of price distortions. ${ }^{43}$

Figure 5. Results of the SADF Date-stamping Procedure for The Log Price to Rent Ratio (1999:M1-2013:M7)

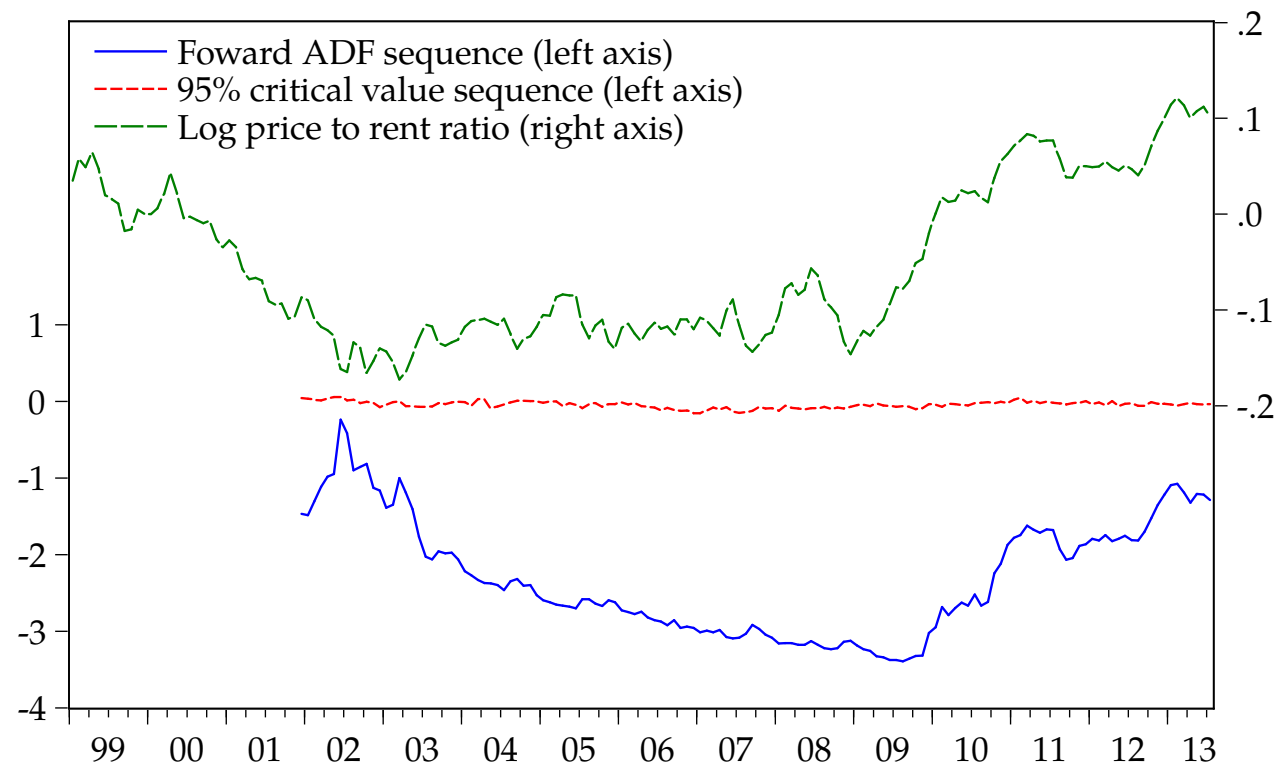

Notes: The figure presents the results of the $\operatorname{SADF}\left(r_{0}=36\right)$ procedure for the natural logarithms of log price to rent ratio index (dashed, green) for the sample period of 1999:M1-2013:M7. The recursive ADF sequence (solid, blue) was estimated with a 3-lag specification. The sequence of critical values (dotted, red) is derived using a Monte Carlo simulation with 2000 replications where the underlying data are generated by a random walk with normal iid errors.

\footnotetext{
${ }^{41}$ I estimated the indirect inference estimator using Matlab, where I have applied the Euclidean distance metric. The $\mathrm{m}$-file is available on demand.

${ }^{42}$ I have also conducted the SADF test on the price to rent ratio (without log), and on the price to income ratio (with and without log) and was unable to reject the null of no-bubble at conventional levels for either of these indicators. (See Appendix B.)

${ }^{43}$ Recall that according to the date stamping procedure, crossing the threshold from below signals a starting point of a bubble conditioned on the existence of such a bubble, i.e., declaring the starting point of a bubble can only be made in retrospect. However, crossing the threshold from below may be viewed as an early warning sign of a potential bubble.
} 


\subsection{Interest Rates}

Recall that in the previous section I proxy the risk-free rate using the difference between the Bank of Israel interest rate and expected inflation. Though this seems like the reasonable "real world" counterpart to the theoretical $v_{t}$, there may be other relevant interest rates investors face, each capturing some of the special features of the housing market. Other rates include the longer-term real rate and/or the mortgage rate. The former rate is justified by the fact that buying a home is a long term decision that must incorporate more forward looking behavior, while the latter is the explicit interest rate most home buyers face due to their ability to use leverage.

To verify the robustness of the main results I apply the same explosiveness test procedure used earlier on the (zero coupon) real interest rate on 10-year government bonds, which represents the long-term risk-free alternative-yield to purchasing a home, and on the average fixed real rate on new mortgages.The data on the zero coupon rate is obtained from the Bank of Israel. ${ }^{44}$ The data on the average mortgage rate are obtained from the Bank of Israel Banking Supervision Department. The average mortgage interest rate is a weighted average of interest rates on new fixed-rate mortgages, where the weights are proportional to the new mortgages' face value.

Table 3 reports the results of the ADF and SADF tests for the noted above different rates. The SADF statistic cannot reject the null of no bubble for either of these rates at conventional significance levels. These findings reinforce the lack of explosiveness found by using the short-term real risk-free rate described in Section 5.1. Nonetheless, these findings are less important for now since the SADF test for the log price to rent ratio does not point to the existence of a bubble.

\subsection{Leverage}

Another important issue which we have ignored thus far is the fact that most home purchases use some amount of leverage (mostly mortgage loans from banks). The question arises as to whether incorporating leverage rates in the present value model affects the previous analysis. To answer this question, I follow Dovman et al. (2012) and present a modified version of the present value model that incorporates leverage.

Consider the following definition of the gross one-period return, $\tilde{V}_{t}$, on holding a home that is partly financed by taking a mortgage:

$$
\tilde{V}_{t}=\frac{P_{t+1}-I_{t}^{m} \lambda_{t} P_{t}+R_{t+1}}{\left(1-\lambda_{t}\right) P_{t}},
$$

${ }^{44}$ The zero coupon rate is derived from an estimate of the real yield curve of Israeli government bonds. 
Table 3. Results of the ADF and SADF Tests for Different Interest Rates

(1) (2)

(3)

\begin{tabular}{|c|c|c|c|}
\hline \multirow[t]{2}{*}{ Series } & \multicolumn{3}{|c|}{ Test statistics } \\
\hline & $\mathrm{ADF}$ & $\underset{\left(r_{0}=36\right)}{\text { SADF }}$ & Maximum date \\
\hline Zero coupon 10-year real rate & -0.792 & -0.331 & 2008:M5 \\
\hline \multirow[t]{2}{*}{ Average fixed mortgage real rate ${ }^{b}$} & -0.842 & -0.565 & 2010:M3 \\
\hline & \multicolumn{2}{|c|}{ Critical values } & \\
\hline $99 \%$ & 0.592 & 1.891 & \\
\hline $95 \%$ & -0.090 & 1.262 & \\
\hline $90 \%$ & -0.425 & 0.978 & \\
\hline
\end{tabular}

Notes: The table reports the estimated ADF and SADF statistics for different interest rates. All unit root test equations include zero lags. Critical values for all statistics are derived using Monte Carlo simulation with 10,000 replications where the underlying data are generated by a random walk with normal iid errors.

a Sample: 1999:M1-2013:M7.

b Sample: 2003:M12-2013:M5.

where $I_{t}^{m}$ is the gross mortgage rate and $\lambda_{t}$ is the leverage rate. Eq. (19) states that the ex post one-period gross return $\tilde{V}_{t}$ is the ratio between the income from period $t+1$ future selling price plus rent minus the interest rate paid on the mortgage that covered a fraction $\lambda_{t}$ of the home value at time $t$, and the equity paid in time $t$. Rearranging Eq. (19) yields

$$
V_{t}=\frac{P_{t+1}+R_{t+1}}{P_{t}}
$$

where now

$$
V_{t}=\left(1-\lambda_{t}\right) \tilde{V}_{t}+\lambda_{t} I_{t}^{m}
$$

is the gross return adjusted to leverage. In other words, $V_{t}$ is the gross return left for the investor after paying down the mortgage (principle plus interest). Eq. (20) is nearly identical to Eq. (1) apart for the definition of the gross return. The solution for (20) is thus similar to the one for the model without leverage, only now $V_{t}$ is defined according to Eq. (21). Formally, the leverage-adjusted log price to rent ratio is given as

$$
p_{t}-r_{t}=\frac{\kappa}{1-\rho}+\sum_{i=0}^{\infty} \rho^{i} E_{t}\left(\Delta r_{t+1+i}-v_{t+1+i}\right)+\lim _{i \rightarrow \infty} \rho^{i} E_{t}\left(p_{t+i}-r_{t+i}\right)
$$

where now, $v_{t}=\log \left[\left(1-\lambda_{t}\right) \tilde{V}_{t}+\lambda_{t} I_{t}^{m}\right]$.

In order to verify that $v_{t}$ is not explosive we can use the simple fact that the leverageadjusted gross return in the model is a convex linear combination of the risk-free rate (and the risk premium) $\tilde{V}_{t}$ and the mortgage interest rate $I_{t}^{m}$, where the weights are determined by the leverage rate $\lambda_{t}$ such that $0 \leq \lambda_{t} \leq 1$. Thus, in order to conclude that 
$v_{t}$ is non-explosive it is sufficient to verify that the risk-free rate and the mortgage rate are non-explosive. ${ }^{45}$ Recalling the results presented in Table 3 that ruled out explosiveness in the average mortgage interest rate and the fact that none of the proxies for the risk-free rate are found explosive, we can conclude that $v_{t}$ is not explosive.

\subsection{A Comparison with Other Detection Methods}

To gain more perspective about the plausibility of my main findings, I compare the results with those of other bubble detection strategies. First, I apply the CUSUM procedure developed by Homm and Breitung (2012) to the log price to rent ratio. ${ }^{46}$ To be consistent with the SADF procedure I set the training sample to 36 observations. The 95\% critical values sequence of the test are obtained by Monte Carlo simulation with 10,000 replications, where the underlying data are generated by a random walk with normal iid errors.

The results of the CUSUM test are presented in Figure 6. As we can see, the CUSUM test statistic (solid, blue) does not cross the $95 \%$ critical value threshold anywhere during the sample, thus not indicating any shift toward an explosive regime. This, of course, is in line with the results of the SADF test presented in the previous section.

Next, I compare the results to Dovman et al. (2012) who also test for a housing bubble in Israel during 2008-10. ${ }^{47}$ Dovman et al. (2012) use several bubble identification schemes, and find no strong evidence of a bubble (as of August 2010). These schemes include: a direct estimate of the fundamental price using ex post or forecast rent payments and ex post and future interest rates (depending on the availability of the data); an estimate of the bubble as an unobserved component using a Kalman filter, as in Wu (1995); and an estimate of the fundamental price and rent to price ratio using linear regression and filtering techniques.

Before I turn to a comparison with the study by Dovman et al. (2012), a remark about the methodological differences is worth making. While Dovman et al. (2012) estimate different measures of the fundamental price and use it to derive the size of the bubble component, the PWY method I use indirectly identifies a bubble based on the dynamic properties of the data. Hence, my results can only give an answer as to whether the null

\footnotetext{
${ }^{45} V_{t}$ is bounded between $\tilde{V}_{t}$ (when $\lambda_{t}=0$ ) and $V_{t}^{m}$ (when $\lambda_{t}=1$ ). Since the natural logarithm function is a monotonic transformation, $v_{t}$ is also bounded between $\tilde{v}_{t}$ and $i_{t}^{m}$ (where $i_{t}^{m} \equiv \log I_{t}^{m}$ )

${ }^{46}$ I owe this part to a suggestion from an anonymous referee.

${ }^{47}$ There is another recent study by Nagar and Segal (2010) who estimate a model of the Israeli housing market using cointegration methods and investigates departures from the long run levels of home prices and rent. I choose not to refer to their analysis in this comparison since despite relating to the possibility of a bubble, the authors do not explicitly model or estimate it. More specifically, in the theoretical section Nagar and Segal (2010) assume that the transversality condition holds, thus they implicitly rule out rational bubbles.
} 
Figure 6. Results of the CUSUM Monitoring Procedure for the Log Price to Rent Ratio (2003:M12-2013:M7)

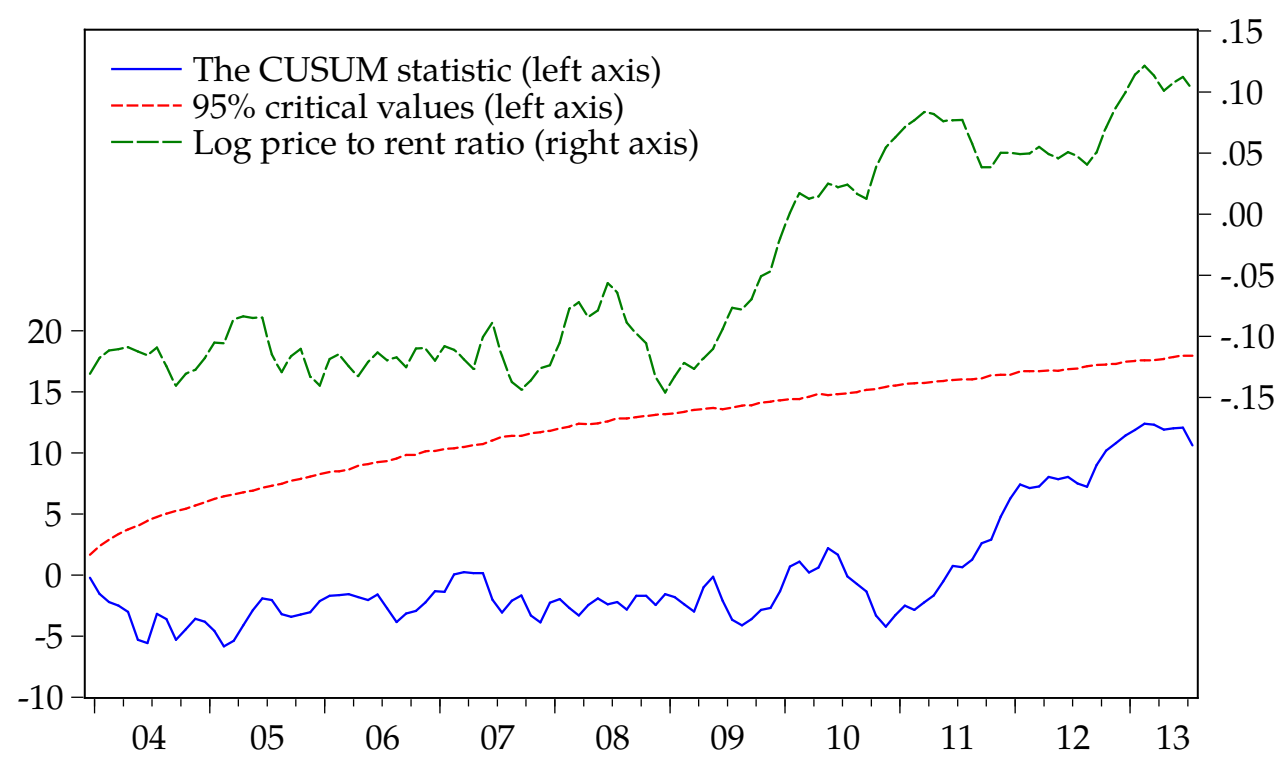

Notes: The figure presents the results of the CUSUM test for the natural logarithms of log price to rent ratio index (dashed, green) for the sample period of 1999:M1-2013:M7. The CUSUM test statistics sequence (solid, blue) is calculated according to Eq. (15) where the training sample is set to 36 observations. The sequence of $95 \%$ critical values (dotted, red) is derived using a Monte Carlo simulation with 10,000 replications, where the underlying data are generated by a random walk with normal iid errors.

of no-bubble can be rejected or not, without specifying a measure of magnitude of the bubble. In contrast, the methods used by Dovman et al. (2012) result in quantitative measures of the bubble component itself, without providing a clear statistical threshold to test whether such a bubble exists.

Figure 7 presents two of the housing bubble indicators developed by Dovman et al. (2012) (and updated to July 2013), based on the direct and the unobserved component methods, for the period of January 1999 to July 2013. Both these indicators are essentially estimates of the bubble components measured in terms of the percent deviations of the observed price from the fundamental price (in this case a value of zero indicates that no bubble exists). As we can see, and in contrast with my findings, both indicators point to the existence of a bubble over most of the sample in question. Measured price distortion reaches up to a $40 \%$ overvaluation in the beginning of the sample, according to the direct method (blue, solid), and up to a 20\% overvaluation in July 2013 according to the unobserved component method(red, dotted). Moreover, there seem to be periods where the bubble component is found to be negative, thus violating the argument made by Diba and Grossman (1988b) about the impossibility of negative bubbles. This highlights the difficulty in measuring bubbles as residuals since these can also be the result of a misspecification of the model, and there is no easy way of distinguishing between the two (Gürkaynak, 2008). 
Figure 7. Alternative Housing Bubble Indicators for Israel Based on Dovman et al. (2012)

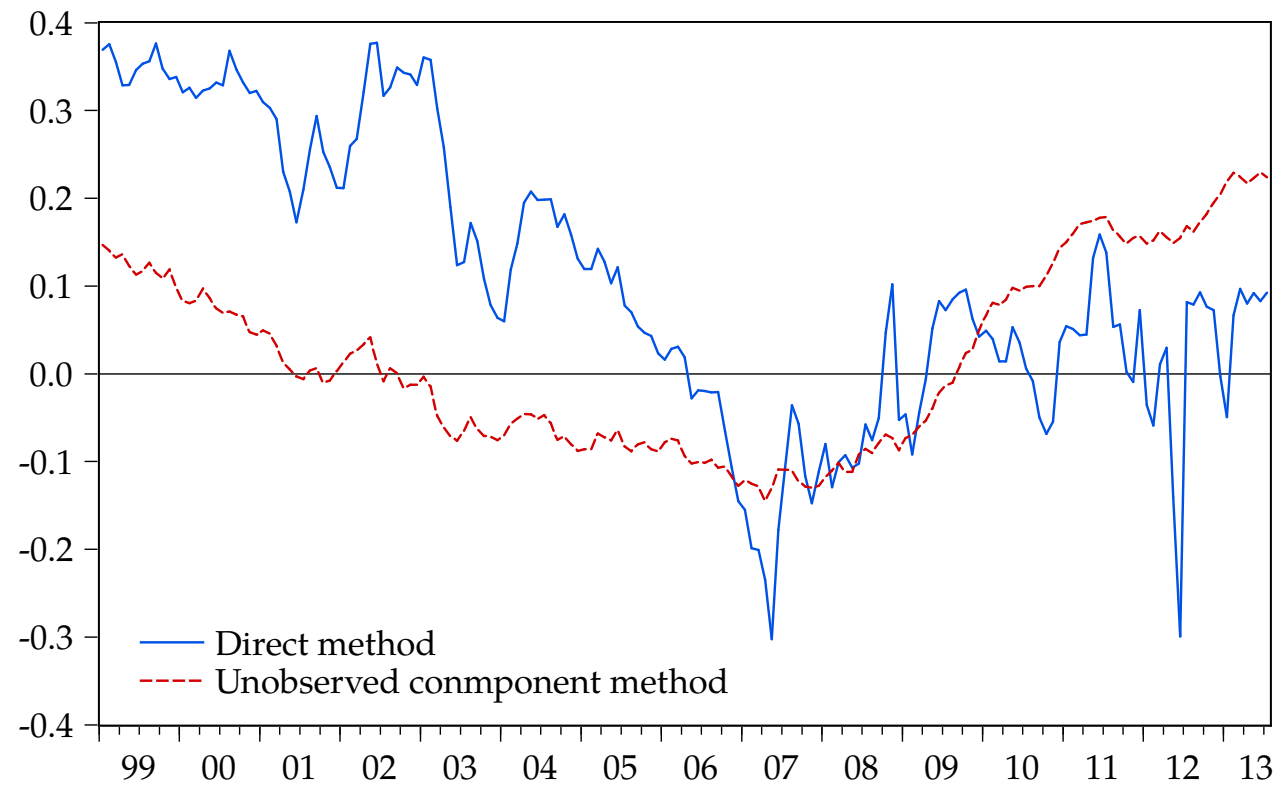

Notes: Monthly data for the period January 1999-July 2013. Both indicators are in terms of percent deviations of observed prices from the fundamental price. These two bubble indicators are calculated in Dovman et al. (2012). In the direct method (solid, blue) the fundamental price is calculated as the sum of ex post rent payments discounted by forward rates. (The authors used forecast values for out-of-sample rent data.) In the unobserved component method (dashed, red), the bubble component is extracted as an unobserved variable using the Kalman filter.

Source: Dovman et al. (2012), updated by the Bank of Israel.

\subsection{Regional Level}

Regional-level analysis is quite common in the empirical literature on housing bubbles (Himmelberg et al., 2005; Case and Shiller, 2003; Smith and Smith, 2006; Clark and Coggin, 2011, to name a few.). This type of analysis takes into account the possibility of housing markets in different regions not being fully integrated. Accordingly, inference based on national level data might be biased toward not rejecting the null of no-bubble in cases where only a small portion of the national housing market manifests explosive behavior. Hence, though we may be able to rule out the possibility of there being a housing bubble at the national level, we need to make sure we are not missing a housing bubble in one or more of Israel's regions.

I now turn to an analysis of the log price to rent ratio at the regional level. I estimate the ADF and SADF statistics for nine regional log price to rent ratios. The minimal window size is set to 20 observations ( 5 years, $\approx 30 \%$ of the sample). ${ }^{48}$ The optimal lag length in all of the recursions is set according to the SIC when applying it to the whole sample (with the maximum number of lags set to 10.) Accordingly, the SIC selects an optimal lag length of zero for all regions but one. The exception is the Krayot region

${ }^{48} \mathrm{~A}$ table with a sensitivity analysis for changing the minimal window size is presented in Appendix $\mathrm{B}$. 
where the selected optimal number of lags is one. The SADF test is not applied to the risk-free rate since the same interest rate is relevant to all regions, and the results of the SADF test for the interest rate have already been presented above. Explosiveness test results for mean rent by region are not presented to preserve space, but none of them points toward a rejection of the null hypothesis.

Table 4 reports the results of right-tailed $\operatorname{ADF}$ and $\operatorname{SADF}\left(r_{0}=20\right)$ tests for the regional $\log$ price to rent ratios. According to the SADF test statistics, reported in the column (2), the no-bubble hypothesis cannot be rejected for the pooled mean price to rent ratio of all nine regions (under the label "ALL" in the table) at conventional significance levels. The SADF statistic, valued at -1.002 (second column), is well below its $90 \%$ right tail critical value of 0.794 . This finding is consistent with the results for the national level. Moreover, we cannot reject the null of no-bubble for all regions at conventional significance levels. The majority of the results of the SADF test for most regions are shown to be robust to different choices of lag length and window size. (See Appendix B.) The only exception is the Gush Dan region where results are sensitive to the choice of lag length. For example, the null of no-bubble in the Gush Dan region is rejected at the 95\% significance level when the test equation includes 3 lags and at the 90\% level when it includes 4 lags.

Table 4. Results of the SADF Test for the Regional Price to Rent Ratios

$(1)$

Region

\begin{tabular}{lccc}
\hline & $A D F$ & $\begin{array}{c}S A D F \\
\left(r_{0}=20\right)\end{array}$ & Maximum date \\
\cline { 2 - 3 } All & -1.312 & -1.002 & $2008: \mathrm{Q} 3$ \\
Tel-Aviv & -1.531 & -0.888 & $2011: \mathrm{Q} 1$ \\
Jerusalem & -0.613 & -0.003 & $2011: \mathrm{Q} 3$ \\
Haifa & -1.755 & -1.253 & $2002: \mathrm{Q} 4$ \\
Gush-Dan & -0.921 & -0.390 & $2010: \mathrm{Q} 2$ \\
Center & -1.153 & -0.910 & $2011: \mathrm{Q} 2$ \\
North & -1.595 & -1.595 & $2013: \mathrm{Q} 2$ \\
South & -1.057 & -0.452 & $2011: \mathrm{Q} 1$ \\
Hasharon & -1.256 & -0.420 & $2008: \mathrm{Q} 2$ \\
Krayot & -1.056 & -1.125 & $2002: \mathrm{Q} 4$ \\
\hline & \multicolumn{2}{c}{ Critical Values } & \\
$99 \%$ & 0.623 & 1.807 & \\
$95 \%$ & -0.044 & 1.118 & \\
$90 \%$ & -0.415 & 0.794 & \\
\hline
\end{tabular}

Notes: The table reports the estimated ADF and SADF test statistics for the sample of 1998:Q1-2013:Q2. In the SADF procedure the initial window size is set to 20 quarters. All test equations do not include lags, apart from the equation for the Krayot region which includes one lag. Critical values for all statistics are derived using a Monte Carlo simulation with 10,000 replications where the underlying data are generated by a random walk with normal iid errors.

The ADF test statistic, reported in column (1), cannot reject the null of no-bubble at conventional significance levels for all regions. (The region which is "closest" to rejection 
is Jerusalem, where the $p$-value for such rejection is 0.14.) Moreover, the SADF statistic exceeds the ADF statistic for all regions. That is, the latest value of the $\mathrm{ADF}_{r_{2}}^{0}$ statistic sequence for all regions is below the maximal value of the sequence. Nonetheless, as is evident in the fourth column of the table, six out of the nine regions reached a peak somewhere during the last 2-3 years. This is consistent with the recent rapid price appreciation, yet it does not point to the existence of a bubble in any of these regions.

\section{Sensitivity Analysis}

\subsection{Lag Length and Minimal Window Size}

It is well known that unit root test results may be sensitive to the specification of the test equation. Moreover, the need to set a minimum window size for the recursive procedure of the SADF test adds more complexity, which might result in additional sensitivity of the results to various chosen minimal window sizes.

Recall that in deriving the results for the national level (Section 5.1) I chose to estimate the ADF auxiliary regression with a lag length of 3 and to set the minimal window size to 36 observations. I now check the sensitivity of these results to different choices of lag length and window size. Before proceeding we must set some upper limit of the number of lags I experiment with. To do so, I note that when conducting the ADF test for the whole sample the AIC and SIC suggest using an optimal lag length of 3 and 6, respectively. Thus, for this analysis I set the what is chosen by the AIC as the upper bound for the lag length. As for the minimal window size, I choose a minimum length of 12 observations (i.e one year). The choice of 12 observations as a lower bound is quite arbitrary, yet using less than 12 observations, especially when there are up to six lags included in the equation, seems unreasonable.

Table 5 shows the robustness of the main results, presented in Section 5.1, to various selections of lag lengths and window sizes. ${ }^{49}$ As we can see, neither of the SADF statistics for a particular choice of lag length and window size is significant at the $95 \%$ level. Moreover, we can see that the choice of lag length does not matter at the window size used to derive the main results $\left(r_{0}=36\right)$. The only case were we are able to reject the null at the $90 \%$ significance level is for $r_{0}=24$ and $k=6$. The evidence shown in Table 5 leads me to conclude that the rejection of the null of no-bubble at the national level is robust to these alternative specifications.

\footnotetext{
${ }^{49}$ In order to make all statistics comparable, I set the first observation of the sample to 1999:M8, namely
} 1999:M1 plus the maximum number of lags plus one. 
Table 5. Sensitivity of the SADF Test for the Log Price to Rent Ratio to Specifications of Lag Length and Window Sizes
(1)
(2)
(3)
$(4)$

(5)

\begin{tabular}{lccccc} 
Lag length & \multicolumn{5}{c}{ Minimal window size } \\
\hline & $r_{0}=12$ & $r_{0}=24$ & $r_{0}=36$ & $r_{0}=60$ & $r_{0}=120$ \\
\cline { 2 - 6 }$k=1$ (fixed) & 0.324 & 0.324 & 0.196 & -0.639 & -0.639 \\
$k=2$ (fixed) & 0.767 & 0.767 & 0.589 & -0.044 & -0.044 \\
$k=3$ (fixed) & 0.551 & 0.551 & 0.285 & -0.619 & -0.619 \\
$k=4$ (fixed) & 0.709 & 0.709 & 0.397 & -0.530 & -0.530 \\
$k=5$ (fixed) & 0.670 & 0.670 & 0.342 & -0.606 & -0.606 \\
$k=6$ (fixed) & 1.103 & $1.103^{*}$ & 0.681 & -0.243 & -0.243 \\
Auto selection - AIC & 1.103 & $1.103^{*}$ & 0.502 & -0.243 & -0.243 \\
Auto selection - SIC & 0.551 & 0.551 & 0.285 & -0.619 & -0.619 \\
\hline & \multicolumn{5}{c}{ Critical values $^{\text {a }}$} \\
$99 \%$ & 2.108 & 1.941 & 1.847 & 1.707 & 1.394 \\
$95 \%$ & 1.470 & 1.332 & 1.243 & 1.095 & 0.681 \\
$90 \%$ & 1.162 & 1.034 & 0.938 & 0.783 & 0.323 \\
\hline
\end{tabular}

Notes: The table reports the estimated SADF statistics for the national level log price to rent ratio, estimated over 1999:M1-2013:M7 for different choices of lag length and minimal window size. Critical values for all statistics are derived using Monte Carlo simulation with 10,000 replications where the underlying data are generated by a random walk with normal iid errors.

${ }^{\text {a I denote by }}{ }^{*},{ }^{* *}$ and ${ }^{* * *}$ rejection at the $90 \%, 95 \%$ and $99 \%$ significance levels, respectively.

\subsection{Sample Period}

My choice of the sample period was dictated by the availability of the data. More specifically, January 1999 is the first month when the rent index in its current format of renewed contracts took effect. However, the home prices index in its current format is available since January $1994 .{ }^{50}$ To see whether using a longer sample has any effect on the main findings, I follow Dovman et al. (2012) and concatenate data from the existing rent contracts index for the period of January 1994 to December 1998 to the Owner Occupied Dwellings Services Price Index (which includes new and renewed contracts). ${ }^{51}$ Figure 8 shows the extended price, rent and price to rent ratios (in logs) for the period starting from January 1994. One interesting feature shown by the graphs is that the current level of the log price to rent ratio is lower than its level in the mid-1990s.

The results of the right-tail ADF and SADF test statistics and critical values for the sample starting from January 1994 are reported in Table 6 along with a comparison with the results from the previous section. None of the test statistics for the ratio, rent and interest rate are able to reject the null of no-bubble in the longer sample.

\footnotetext{
${ }^{50}$ The sample issue is irrelevant to the regional analysis since data for mean rent payments only exists since the first quarter of 1998.

${ }^{51}$ Clearly, a rent index based on existing rent does not properly reflect real time conditions of the housing market but rather the ones at the time they were signed.
} 
Figure 8. Time Series Plots - Extended Sample (1994:M1 - 2013:M7)

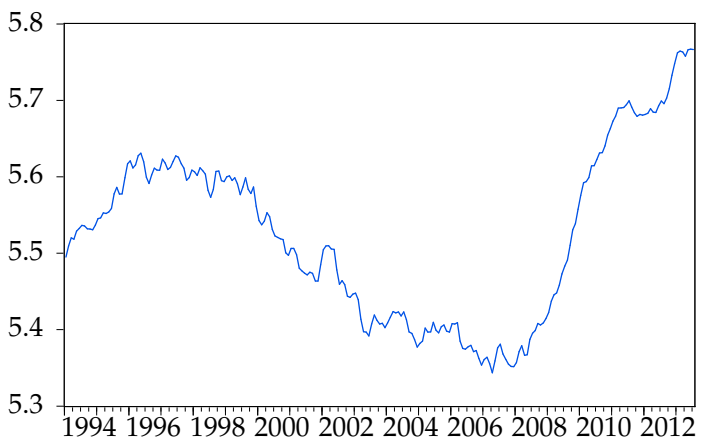

(a) Log real price $p_{t}$

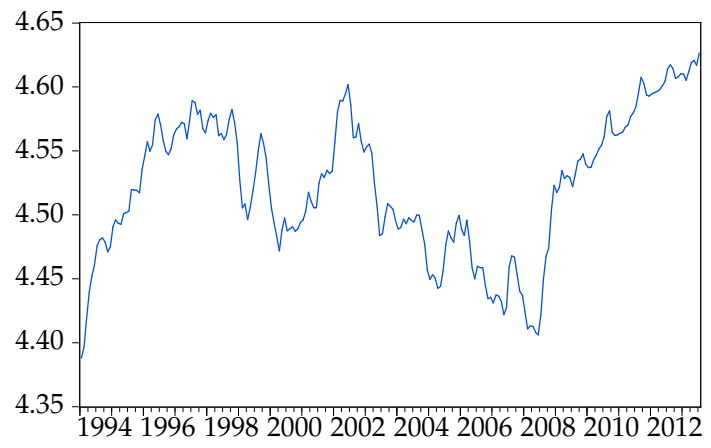

(b) Log real rent $r_{t}$

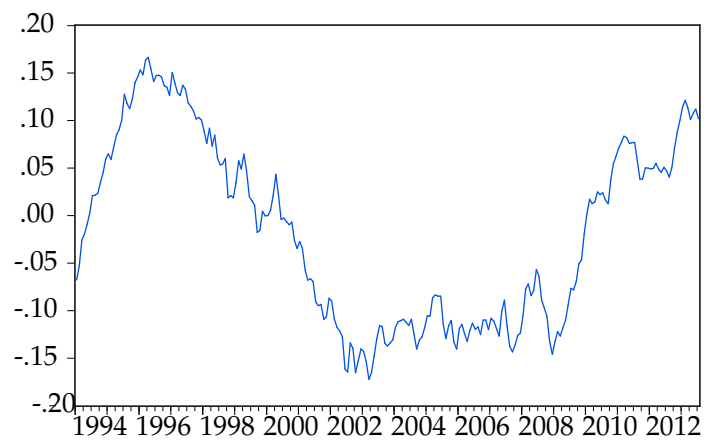

(c) $\log$ price to rent ratio $p_{t}-r_{t}$

Notes: Log home prices $\left(p_{t}\right)$ and log rent $\left(r_{t}\right)$ indices are deflated by the CPI. Log price to rent ratio $\left(p_{t}-r_{t}\right)$ is an index, normalized to January $2000=0$. The real risk-free rate $\left(v_{t}\right)$ is given by the difference between $\mathrm{BOI}$ interest rate and expected inflation (see Appendix $\mathrm{C}$ for further details).

Table 6. Results of the Test for Explosive Behavior Using an Extended Sample

(1)

Sample: 1994:M1-2013:M7
(3)

(4)

Test statistics

\begin{tabular}{|c|c|c|c|c|}
\hline & $\mathrm{ADF}$ & $\underset{\left(r_{0}=36\right)}{\mathrm{SADF}}$ & $\mathrm{ADF}$ & $\underset{\left(r_{0}=36\right)}{\operatorname{SADF}}$ \\
\hline Log price to rent ratio $p_{t}-r_{t}$ & -0.962 & 0.617 & -1.286 & -0.237 \\
\hline Log real rent $r_{t}$ & -1.907 & -1.674 & -1.495 & -0.780 \\
\hline \multirow[t]{2}{*}{ Log gross real risk-free rate $i_{t}$} & -1.706 & -1.315 & -1.811 & 0.983 \\
\hline & \multicolumn{4}{|c|}{ Critical values } \\
\hline $99 \%$ & 0.621 & 1.952 & 0.592 & 1.891 \\
\hline $95 \%$ & -0.005 & 1.346 & -0.090 & 1.262 \\
\hline $90 \%$ & -0.402 & 1.042 & -0.425 & 0.978 \\
\hline
\end{tabular}

Notes: The table reports the estimated ADF and $\operatorname{SADF}\left(r_{0}=36\right)$ statistics for the extended sample (1994:M12013:M7) and for the baseline sample (1999:M1-2013:M7). All unit root test equations include 3 lags. Critical values for all statistics are derived using a Monte Carlo simulation with 10,000 replications where the underlying data are generated by a random walk with normal iid errors. 
Next, I check whether the results within the original sample (1999:M1-2013:M7) are sensitive to the choice of the initial observation. To do so I implement the generalized SADF (GSADF) suggested by Phillips et al. (2013b, hereinafter: PSY). This strategy generalizes the SADF test by allowing a more flexible estimation window, wherein, unlike the SADF procedure, the starting point, $r_{1}$, is not fixed at 0 but rather is allowed to vary within the range $\left[0, r_{2}-r_{0}\right]$. Formally, the GSADF statistic is defined as

$$
\operatorname{GSADF}\left(r_{0}\right)=\sup _{\substack{r_{2} \in\left[r_{0}, 1\right] \\ r_{1} \in\left[0, r_{2}-r_{0}\right]}}\left\{\operatorname{ADF}_{r_{1}}^{r_{2}}\right\}
$$

Essentially, the GSADF procedure estimates all possible subsamples of some arbitrary minimum size and above, calculates the $\mathrm{ADF}_{r_{2}}^{r_{1}}$ statistic for each of these subsamples (note that now the ADF statistic also depends on the starting point of the window, $r_{1}$ ), and finds the maximal value of the $\mathrm{ADF}_{r_{2}}^{r_{1}}$ sequence. This maximal value is defined as the GSADF statistic. Phillips et al. (2013b) show that the distribution of the GSADF statistic exists and has a nonstandard form. Thus, critical values are obtained by using Monte Carlo simulation methods. Accordingly, if the GSADF statistic is larger than the corresponding critical value, we reject the null hypothesis of a unit root in favor of a mildly explosive process. ${ }^{52}$

The GSADF statistic and its corresponding critical values for the log price to rent ratio are presented in Table 7 along with a comparison to the previously calculated standard ADF statistic and the SADF statistic. To be consistent with the SADF procedure, I set the lag length to 3 lags and the minimum window size to 36 observations. As we can see, the GSADF statistic for the price to rent ratio is 0.392 , well below the $90 \%$ critical value of 1.281 . Thus, the null of no-bubble hypothesis can also not be rejected by the GSADF statistic.

\section{Conclusion}

This paper examines whether the run-up in Israeli home prices during 2008-2013 (10\% average real annual growth rate) reflects a housing bubble. I address this question by applying the dynamic Gordon growth model and econometric bubble detection and monitoring strategies proposed by Phillips et al. (2011), Phillips et al. (2013b) and Homm and Breitung (2012) to Israeli housing market data at the national level

\footnotetext{
${ }^{52}$ The GSADF procedure can be viewed as a mechanism that 'fines' possible data mining with the SADF procedure. That is, given a specific sample, one can arbitrarily choose any starting point. Experimenting with different samples involves losing degrees of freedom, thus making the SADF critical values invalid. The GSADF procedure takes this into account by computing correct critical values for a procedure that uses the SADF test for every starting point available.
} 
Table 7. Initial Starting Point Sensitivity Check - the GSADF Test

(1)

Series

\begin{tabular}{|c|c|c|c|}
\hline & $A D F$ & $\underset{\left(r_{0}=36\right)}{S A D F}$ & $\underset{\left(r_{0}=36\right)}{G S A D F}$ \\
\hline \multirow[t]{2}{*}{ Log price to rent ratio $p_{t}-r_{t}$} & -1.286 & -0.237 & 0.483 \\
\hline & \multicolumn{3}{|c|}{ Critical values } \\
\hline $99 \%$ & 0.592 & 1.891 & 2.410 \\
\hline $95 \%$ & -0.090 & 1.262 & 1.893 \\
\hline $90 \%$ & -0.425 & 0.978 & 1.613 \\
\hline
\end{tabular}

Notes: The table reports the estimated ADF, SADF and GSADF statistics for the sample 1999:M1-2013:M7 with initial window sizes set to 36 months ( 3 years). All unit root test equations include 3 lags. Critical values for all statistics are derived using a Monte Carlo simulation with 10,000 replications, where the underlying data are generated by a random walk with normal iid errors.

(1999:M1-2013:M7) and to nine regions (1998:Q1-2013:Q2). Overall, the null hypothesis of no-bubble cannot be rejected for the Israeli data. The results for the national level data and for most of the regional level data are robust to a variety of tests, model specifications and to consideration of leverage and mortgage rates. One exception is the Gush Dan region, where results are rather inconclusive due to their sensitivity to the choice of lag length in the test equation. I conclude that the recent run-up in home prices is likely to be the outcome of changes in fundamental factors (rent and interest rates). The integrated theoretical and empirical frameworks presented here for the Israeli case could be applied to other countries sharing similar developments in their housing markets.

\section{Appendix A Approximation Accuracy Analysis}

The validity of the conclusions rising from the theoretical and empirical section rely heavily on the accuracy of the Campbell-Shiller log linear approximation procedure. The approximation, stated in price to rent ratio terms, is given as

$$
p_{t}-r_{t} \approx \kappa-v_{t+1}+\Delta r_{t+1}+\rho\left(p_{t+1}-r_{t+1}\right)
$$

where $\kappa$ and $\rho$ are both functions of the linearization point, which in our case is the sample mean log rent to price ratio, denoted as $\overline{r-p}$. Clearly, as in any other Taylor expansion, large deviations of the true relation from the approximated one will result in little reliance on the interpretation of the model. Thus, the approximation error between the left hand side and the right hand side of (A.1) must be investigated.

Formally, the approximation error can be defined by writing the exact form of (A.1) 


$$
p_{t}-r_{t}=\kappa-v_{t+1}+\Delta r_{t+1}+\rho\left(p_{t+1}-r_{t+1}\right)+e_{t}
$$

where $e_{t}$ is the approximation error. Summarizing several statistical properties of $e_{t}$ such as the mean, and the percent deviation from the non-approximated value, along with a comparison of the approximated log ratio with the actual log ratio, can thus shed light on the validity of the approximation and the results that follow. The literature contains several studies aimed at examining the accuracy of the CampbellShiller approximation. One recent example, in the context of rational bubbles is Engsted et al. (2012), where the authors apply Monte Carlo methods to investigate the error of the log linear approximation, both under stationarity and under explosiveness of the $\log$ price to dividend ratio. The authors find that under constant returns, the error is quite small, even in the presence of relatively large bubbles.

Despite the general results obtained in Engsted et al. (2012), an examination of my specific case is still necessary because each case may have its own special properties. Before proceeding to an analysis of the approximation error, a few preliminary steps need to be taken. First, in order to calculate the approximated ratio, we need to use log returns $v_{t}$. However, when compiling the log price to rent ratio at the national level, I used the home price and rent indices. Though using indices enables us to construct an index of the log price to rent ratio that reliably describes developments in the ratio, it does not enable us to calculate returns. Calculating returns can only be done if we have measures of the levels of home prices and rent. To overcome this obstacle, I proceed with a few simplifying assumptions. First, I turn to the data on the aggregate average price and rent for 3.5-4 room apartments, used in the regional level analysis, and assume that the average home price and rent observed in the first quarter of 2000 are the true values that hold at the national level in January 2000. Next, I assume that the development (i.e., growth rates) of prices and rent follow what is implied by the home price and rent indices throughout the rest of the period 1999:M1-2013:M7. Using these artificial series enables us to calculate all that is needed for the log linear approximation, including home prices, rent and returns.

Deriving the approximated ratio depends on the constants of linearization $\kappa$ and $\rho$, which are functions of the linearization point-the mean log rent to price ratio $\overline{r-p}$. In the specific sample I use, these parameters equal

$$
\begin{aligned}
& \overline{r-p}=-3.046 \\
& \rho=1 /\left[1+e^{(\overline{r-p})}\right]=0.956 \\
& \kappa=-\log (\rho)-(1-\rho) \log \left(\frac{1}{\rho}-1\right)=0.185 .
\end{aligned}
$$


Using these parameters along with prices, rent and returns series, I calculate the approximated price to rent ratio defined by Eq. (A.1). The results of this exercise are presented in Figure A1. The figure shows the actual log price to rent ratio, the approximated ratio and the approximation error (in percent). The log ratio (solid, blue) and its corresponding approximation (dotted, red) are quite indistinguishable during the sample period. Moreover, the sample correlation between the two series is close to 1 , and the correlograms of both series (not presented) are nearly identical. Hence, both series exhibit very similar dynamics. Since the test for explosiveness relies on these dynamics for inference, this finding is important. A closer inspection of the differences between the log ratio and the approximation is made using the percent error of approximation (dashed, green). As the figure shows, the maximal value of percent error is valued at around $0.02 \%$, while its sample mean stands below $0.005 \%$. These results indicate a negligible error of approximation, thus further validating the use I made of the Campbell-Shiller linearization method.

Figure A1. Actual, Approximated and the Error of Approximation of the Log Price to Rent Ratio at the National Level (1999:M1-2013:M7)

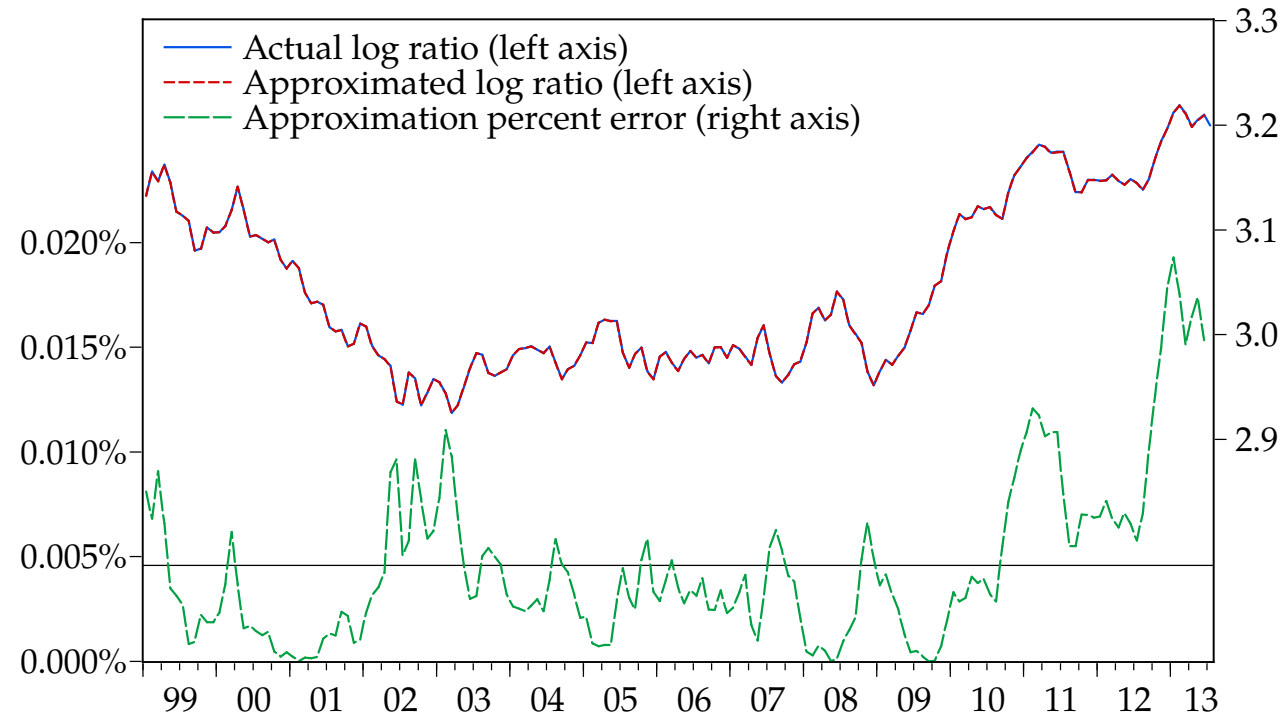

Notes: The solid black line presents the sample mean of the approximation error (dashed, green). Positive values of the error term mean that the log ratio is underestimated by the approximated log ratio.

The same analysis is performed on the regional level data. In this case, since prices and rent are already given in their nominal values, the calculation is straightforward. For example, for the Tel Aviv region, the parameters of the approximation are given by

$$
\begin{aligned}
& \overline{r-p}=-3.333 \\
& \rho=1 /\left[1+e^{(\overline{r-p})}\right]=0.966 \\
& \kappa=-\log (\rho)-(1-\rho) \log \left(\frac{1}{\rho}-1\right)=0.150 .
\end{aligned}
$$


The picture that emerges from the approximation for the Tel Aviv region ratio, presented in Figure A2, is very similar to the one presented for the national level region data. The approximation percent error (dashed, green) is maxed at $0.05 \%$ while its sample mean stands at around $0.01 \%$. Here also I can reasonably conclude that the error is negligible and that the approximated ratio retains the dynamic properties of the actual ratio. Similar findings hold for all other eight regions analyzed in Section 5.5 (not presented).

Figure A2. Actual, Approximated and the Error of Approximation of the Log Price to Rent Ratio for the Tel Aviv Area (1998:Q1-2013:Q2)

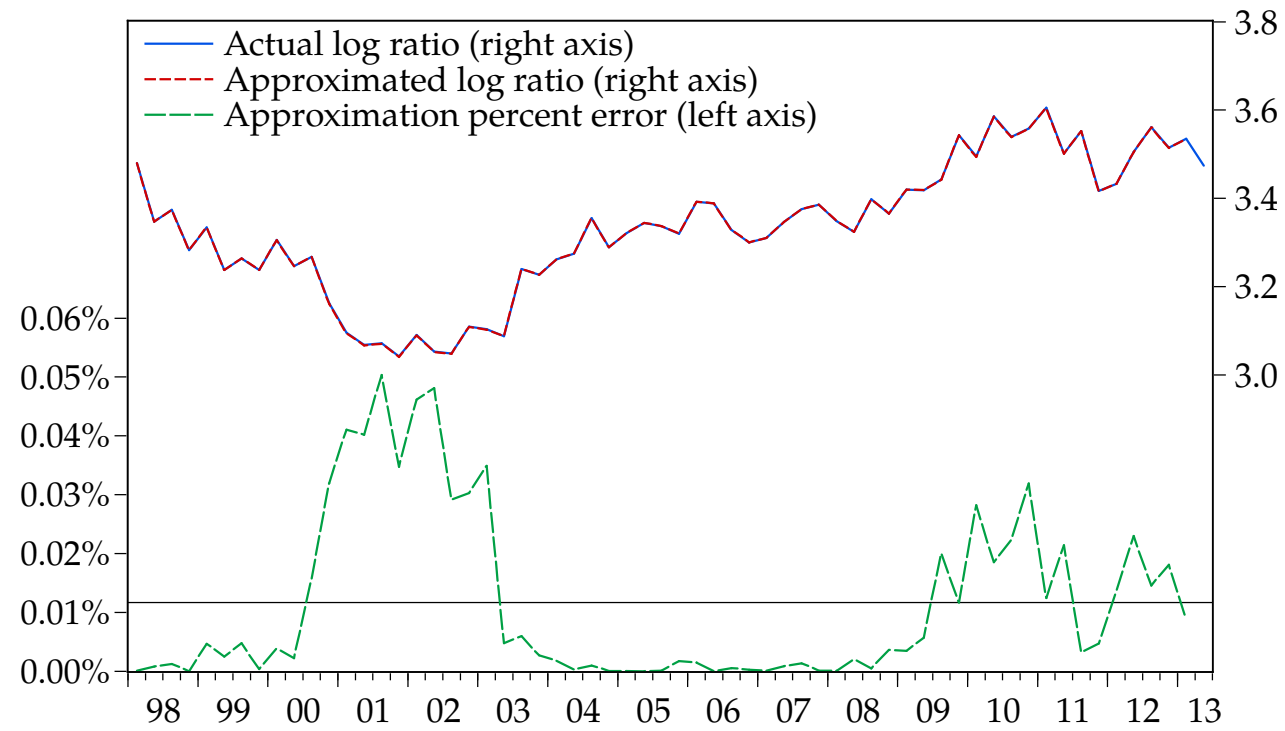

Notes: The solid black line presents the sample mean of the approximation error (dashed, green). Positive values of the error term mean that the log ratio is underestimated by the approximated log ratio. 


\section{Appendix B Further Sensitivity Analysis}

Table B1. Sensitivity of the SADF test for the Local Price to Rent Ratios to the Choice of Minimal Window Size
(1)
(2)
(3)
(4)
(5)

Area

Test statistic

\begin{tabular}{lccccc}
\hline & $A D F$ & $\begin{array}{c}S A D F \\
\left(r_{0}=16\right)\end{array}$ & Maximum date & $\begin{array}{c}S A D F \\
\left(r_{0}=24\right)\end{array}$ & Maximum date \\
\cline { 2 - 6 } Total & -1.312 & 0.080 & $2001 \mathrm{Q} 4$ & -1.002 & 2008Q3 \\
Tel Aviv & -1.531 & -0.888 & $2011 \mathrm{Q} 1$ & -0.888 & 2011Q1 \\
Jerusalem & -0.613 & -0.003 & $2011 \mathrm{Q} 3$ & -0.003 & 2011Q3 \\
Haifa & -1.755 & -0.906 & $2002 \mathrm{Q} 2$ & -1.597 & 2011Q2 \\
Gush Dan & -0.921 & -0.390 & $2010 \mathrm{Q} 2$ & -0.390 & 2010Q2 \\
Center & -1.153 & 0.340 & $2001 \mathrm{Q} 2$ & -0.910 & 2011Q2 \\
North & -1.595 & -1.454 & $2000 \mathrm{Q} 4$ & -1.595 & 2013Q2 \\
South & -1.057 & -0.452 & $2011 \mathrm{Q} 1$ & -0.452 & $2011 \mathrm{Q} 1$ \\
Hasharon & -1.256 & -0.420 & $2008 \mathrm{Q} 2$ & -0.420 & $2008 \mathrm{Q} 2$ \\
Krayot & -1.056 & -0.642 & $2002 \mathrm{Q} 2$ & -0.682 & $2011 \mathrm{Q} 1$ \\
\hline & & & Critical Values & \\
$99 \%$ & 0.557 & 2.008 & & 1.705 & \\
$95 \%$ & -0.053 & 1.310 & & 1.056 & \\
$90 \%$ & -0.414 & 0.998 & & 0.725 & \\
\hline
\end{tabular}

Notes: The table reports the estimated ADF and SADF test statistics for the regional log price to rent ratios, estimated over 1998:Q1-2013:Q2. In the SADF procedure the initial window size is set to 16 and 24 quarters. All test equations include zero lags, apart from the equation for the Krayot region which includes one lag. Critical values for all statistics are derived using a Monte Carlo simulation with 10,000 replications where the underlying data are generated by a random walk with normal iid errors.

Table B2. Results of the ADF and SADF Tests

\begin{tabular}{|c|c|c|c|}
\hline & (1) & (2) & (3) \\
\hline Series & $\mathrm{ADF}$ & $\underset{\left(r_{0}=36\right)}{\text { SADF }}$ & Maximum date \\
\hline Price to rent & -1.265 & -0.520 & 2002:M6 \\
\hline Price to income & -0.716 & -0.698 & 2013:M2 \\
\hline \multirow[t]{2}{*}{ Log price to income } & -0.881 & -0.698 & 2013:M2 \\
\hline & \multicolumn{2}{|c|}{ Critical values } & \\
\hline $99 \%$ & 0.592 & 1.891 & \\
\hline $95 \%$ & -0.090 & 1.262 & \\
\hline $90 \%$ & -0.425 & 0.978 & \\
\hline
\end{tabular}

Notes: The table reports the estimated ADF and SADF statistics and the date where the $\mathrm{ADF}_{0}^{r_{2}}$ sequence has reached its maximum. for the sample 1999:M1-2013:M7 where the initial window sizes is set to 36 months. The unit root test equations include 12 lags for the price to income ratio series (with and without log) and 3 lags for the price to rent ratio series. (Optimal lag length is set according to the SIC.) Critical values for all statistics are derived using Monte Carlo simulation with 10,000 replications where the underlying data are generated by a random walk with normal iid errors. 
Table B3. Sensitivity of the ADF and SADF Test Statistics to Specifications of Lag Lengths

\begin{tabular}{|c|c|c|c|c|c|c|c|c|c|c|}
\hline \multirow[t]{2}{*}{ Region } & \multicolumn{5}{|c|}{ ADF statistic ${ }^{a}$} & \multicolumn{5}{|c|}{$\operatorname{SADF}\left(r_{0}=20\right)$ statistic $^{\mathrm{a}}$} \\
\hline & $k=0$ & $k=1$ & $k=2$ & $k=3$ & $k=4$ & $k=0$ & $k=1$ & $k=2$ & $k=3$ & $k=4$ \\
\hline Total & -1.312 & -0.852 & -0.766 & -0.700 & -1.185 & -1.002 & -0.472 & -0.371 & -0.149 & -0.454 \\
\hline Tel-Aviv & -1.531 & -0.776 & -1.026 & -0.991 & -1.097 & -0.888 & 0.098 & -0.241 & -0.216 & -0.647 \\
\hline Jerusalem & -0.613 & $-0.340^{*}$ & $-0.359^{*}$ & -0.619 & $-0.392^{*}$ & -0.003 & 0.559 & 0.558 & 0.312 & 0.373 \\
\hline Haifa & -1.755 & -1.305 & -0.753 & $-0.293^{*}$ & -0.443 & -1.253 & -1.305 & -0.601 & 0.014 & -0.009 \\
\hline Gus-Dan & -0.921 & -0.796 & -0.602 & $0.062^{* *}$ & $0.135^{* *}$ & -0.390 & -0.306 & 0.002 & $1.146^{* *}$ & $1.104^{*}$ \\
\hline Center & -1.153 & -0.902 & -0.639 & -0.589 & -0.701 & -0.910 & -0.629 & -0.319 & -0.261 & -0.358 \\
\hline North & -1.595 & -1.223 & -0.664 & -0.678 & -0.527 & -1.595 & -1.205 & -0.589 & -0.583 & -0.385 \\
\hline South & -1.057 & -0.933 & -0.889 & -0.860 & -0.918 & -0.452 & -0.278 & -0.269 & -0.053 & 0.432 \\
\hline Hasharon & -1.256 & -1.110 & -0.890 & -0.760 & -0.716 & -0.420 & -0.101 & 0.234 & 0.531 & 0.431 \\
\hline \multirow[t]{2}{*}{ Krayot } & -1.577 & -1.056 & -0.726 & -0.499 & -0.505 & -1.125 & -0.682 & -0.306 & -0.003 & 0.075 \\
\hline & \multicolumn{10}{|c|}{ Critical values $^{\mathrm{b}}$} \\
\hline $99 \%$ & & & 0.623 & & & & & 1.807 & & \\
\hline $95 \%$ & & & -0.044 & & & & & 1.118 & & \\
\hline $90 \%$ & & & -0.415 & & & & & 0.795 & & \\
\hline
\end{tabular}

Notes: The table reports the sensitivity of the regional ADF and $\operatorname{SADF}\left(r_{0}=20\right)$ test statistics for the regional $\log$ price to rent ratio to various choices of lag length $-k=\{0,1,2,3,4\}$. The statistics are estimated over 1998:Q1-2013:Q2. Critical values for all statistics are derived using Monte Carlo simulation with 10,000 replications where the underlying data are generated by a random walk with normal iid errors.

${ }^{a}$ I denote by ${ }^{*}, * *$ and ${ }^{* * *}$ rejection at the $90 \%, 95 \%$ and $99 \%$ significance levels, respectively.

$\mathrm{b}$ The critical values for each test statistic, which appear in the lower panel of this table, apply to all lag lengths

\section{Appendix C Data}

The following section further elaborates on the data used in the empirical analysis.

\section{C.1 National Level}

- Home prices - Home prices are proxied by the hedonic (quality adjusted) Prices of Dwellings Index that is published on a monthly basis by the Israeli Central Bureau of Statistics. The index is based on the survey of prices of owner occupied homes. The index, in its current form, exists since January 1994.

- Rent - Rent prices are proxied by the Owner Occupied Dwellings Services Price Index, included in the CPI and published by the Israeli Central Bureau of Statistics on a monthly basis. Since January 1999 the index is based on new renewed rent contracts. ${ }^{53}$

- Inflation - The change in the Consumer Price Index, published on a monthly basis by the Israeli CBS. The index is calculated as changes in the price of a fixed basket

\footnotetext{
${ }^{53}$ Prior to 1999 the Owner Occupied Dwellings Services Price Index was calculated indirectly using a variation of the home prices index.
} 
of consumer goods.

- Short-term risk-free real interest rate - This interest rate is calculated as the difference between the Bank of Israel's official benchmark rate on monetary loans and expected inflation derived from the spread between CPI indexed and unindexed government bonds. Both the monetary rate and expected inflation are obtained from the Bank of Israel.

\section{C.2 Regional Level}

- Home prices and rent - average prices of owner occupied dwellings (purchase price) and rent for 3.5-4 room apartments, in nominal terms (current shekels), classified for nine geographic regions (see Table C1). ${ }^{54}$ The data are published on a quarterly basis by the Israeli CBS. The aggregate average level of home prices and rent are calculated as a weighted sum of the different regions, where the weights for each region are determined by the proportion of the region's value of homes out of the total.

\footnotetext{
${ }^{54}$ In Israel, the kitchen is not counted as a room, and half a room often refers to a small room.
} 
Table C1. Geographic Areas Included in the Average Quarterly Dwelling Prices and Rent

\begin{tabular}{|c|c|}
\hline Area & Localities \\
\hline Jerusalem & Jerusalem \\
\hline Tel Aviv & Tel Aviv-Yafo \\
\hline Haifa & Haifa \\
\hline Gush Dan & $\begin{array}{l}\text { Bnei Brak, Bat Yam, Giv'atayim, Holon, } \\
\text { Ramat Gan }\end{array}$ \\
\hline Center and Jerusalem Periphery Towns & $\begin{array}{l}\text { Or Yehuda, El'ad, Bet Shemesh, Betar Illit, } \\
\text { Yavne, Yehud, Lod, Mevasseret Zion, } \\
\text { Modi'in Illit, Ma'ale Adummim, Nes Ziona, Petah Tikva, } \\
\text { Rosh Ha'ayin, Rishon Lezion, Rehovot, Ramla }\end{array}$ \\
\hline South & $\begin{array}{l}\text { Ofakim, Elat, Ashdod, Ashkelon, Be'er Sheva } \\
\text { Gedera, Dimona, Netivot, Arad, } \\
\text { Kiryat Mal'akhi, Sederot }\end{array}$ \\
\hline Sharon & $\begin{array}{l}\text { Hod Hasharon, Herzliya, Hadera, Kefar Sava, } \\
\text { Ramat Hasharon, Ra'anana }\end{array}$ \\
\hline North & $\begin{array}{l}\text { Zikhron Yaakov, Tiberias, Tirat HaCarmel, Yokneam Illit, } \\
\text { Migdal HaEmek, Ma'alot-Tarshiha, Nahariya, Nazareth, } \\
\text { Nesher, Akko, Afula, Pardes Hanna-Karkur } \\
\text { Kiryat Tiv'on, Kiryat Shemona }\end{array}$ \\
\hline Krayot & Kiryat Atta, Kiryat Bialik, Kiryat Yam, Kiryat Motzkin \\
\hline
\end{tabular}

Source: Israeli Central Bureau of Statistics. url: http://www1.cbs.gov.il/www/price_new/a1_3_e.pdf 


\section{References}

Arshanapalli, B. and W. Nelson (2008). A cointegration test to verify the housing bubble. The International Journal of Business and Finance Research 2(2), 35-43.

Ben Basat, A. (2002). The Israeli Economy, 1985-1998: From Government Intervention to Market Economics. MIT Press.

Brunnermeier, M. K. (2008). Bubbles. In S. N. Durlauf and L. E. Blume (Eds.), The New Palgrave Dictionary of Economics. Basingstoke: Palgrave Macmillan.

Campbell, J. Y. and R. J. Shiller (1988). The dividend-price ratio and expectations of future dividends and discount factors. Review of financial studies 1(3), 195-228.

Campbell, S. D., M. A. Davis, J. Gallin, and R. F. Martin (2009). What moves housing markets: A variance decomposition of the rent-price ratio. Journal of Urban Economics 66(2), 90-102.

Case, K. E. and R. J. Shiller (2003). Is there a bubble in the housing market? Brookings Papers on Economic Activity 2003(2), 299-362.

Caspi, I. (2013). Rtadf: Testing for bubbles with EViews.

Clark, S. P. and T. D. Coggin (2011). Was there a us house price bubble? an econometric analysis using national and regional panel data. The Quarterly Review of Economics and Finance 51(2), 189-200.

Diba, B. T. and H. I. Grossman (1988a). Explosive rational bubbles in stock prices? The American Economic Review 78(3), 520-530.

Diba, B. T. and H. I. Grossman (1988b). The theory of rational bubbles in stock prices. The Economic Journal 98(392), 746-754.

Dickey, D. A. and W. A. Fuller (1979). Distribution of the estimators for autoregressive time series with a unit root. Journal of the American Statistical Association 74(366a), 427-431.

Dovman, P., S. Ribon, and Y. Yakhin (2012). The housing market in Israel 2008-2010: Are house prices a 'bubble'? Israel Economic Review 10(1).

Engsted, T., S. J. Hviid, and T. Q. Pedersen (2014). Explosive bubbles in house prices? evidence from the oecd countries. 
Engsted, T., T. Q. Pedersen, and C. Tanggaard (2012). The log-linear return approximation, bubbles, and predictability. Journal of Financial and Quantitative Analysis 47(3), 643.

Evans, G. W. (1991). Pitfalls in testing for explosive bubbles in asset prices. The American Economic Review 81(4), 922-930.

Flood, R. P. and R. J. Hodrick (1990). On testing for speculative bubbles. The Journal of Economic Perspectives 4(2), 85-101.

Froot, K. A. and M. Obstfeld (1992). Intrinsic bubbles: The case of stock prices. Technical report, National Bureau of Economic Research.

Galí, J. (2014). Monetary policy and rational asset price bubbles. The American Economic Review 104(3), 721-752.

Glaeser, E. L., J. Gyourko, and A. Saiz (2008). Housing supply and housing bubbles. Journal of Urban Economics 64(2), 198-217.

Gürkaynak, R. (2008). Econometric tests of asset price bubbles: Taking stock. Journal of Economic Surveys 22(1), 166-186.

Hamilton, J. D. (1986). On testing for self-fulfilling speculative price bubbles. International Economic Review, 545-552.

Himmelberg, C., C. Mayer, and T. Sinai (2005). Assessing high house prices: Bubbles, fundamentals and misperceptions. The Journal of Economic Perspectives 19(4), 67-92.

Homm, U. and J. Breitung (2012). Testing for speculative bubbles in stock markets: a comparison of alternative methods. Journal of Financial Econometrics 10(1), 198-231.

Iraola, M. A. and M. S. Santos (2008). Speculative bubbles. In S. N. Durlauf and L. E. Blume (Eds.), The New Palgrave Dictionary of Economics. Basingstoke: Palgrave Macmillan.

LeRoy, S. F. and R. D. Porter (1981). The present-value relation: Tests based on implied variance bounds. Econometrica: Journal of the Econometric Society, 555-574.

Liviatan, N. (2003). Fiscal dominance and monetary dominance in the Israeli monetary experience. Bank of Israel, Discussion Paper No. 2003.17.

Mack, A. and E. Martínez-García (2011). A cross-country quarterly database of real house prices: a methodological note. Federal Reserve Bank of Dallas Globalization and Monetary Policy Institute Working Paper,,(99). 
MATLAB (2010). version 7.10.0 (R2010a). Natick, Massachusetts: The MathWorks Inc.

McCarthy, J. and R. W. Peach (2004). Are home prices the next 'bubble'? FRBNY Economic Policy Review 10(3), 1-17.

Nagar, W. and G. Segal (2010). What explains the movements in home prices and rent in Israel during 1999-2010? (in Hebrew). Bank of Israel Survey (85), 7—-59.

Pavlidis, E., A. Yusupova, I. Paya, D. Peel, E. Martinez-Garcia, A. Mack, and V. Grossman (2013). Monitoring housing markets for episodes of exuberance: an application of the phillips et al. $(2012,2013)$ gsadf test on the dallas fed international house price database. Federal Reserve Bank of Dallas Globalization and Monetary Policy Institute Working Paper (165).

Phillips, P. C. B. and T. Magdalinos (2007). Limit theory for moderate deviations from a unit root. Journal of Econometrics 136(1), 115-130.

Phillips, P. C. B., S. Shi, and J. Yu (2013a). Specification sensitivity in right-tailed unit root testing for explosive behaviour. Oxford Bulletin of Economics and Statistics.

Phillips, P. C. B., S. Shi, and J. Yu (2013b). Testing for multiple bubbles 1: Historical episodes of exuberance and collapse in the S\&P 500.

Phillips, P. C. B., Y. Wu, and J. Yu (2011). Explosive behavior in the 1990s NASDAQ: When did exuberance escalate asset values? International Economic Review 52(1), 201-226.

Phillips, P. C. B. and J. Yu (2009). Limit theory for dating the origination and collapse of mildly explosive periods in time series data.

Phillips, P. C. B. and J. Yu (2011). Dating the timeline of financial bubbles during the subprime crisis. Quantitative Economics 2(3), 455-491.

Poterba, J. (1984). Tax subsidies to owner-occupied housing: an asset-market approach. The Quarterly Journal of Economics 99(4), 729-752.

Santos, M. S. and M. Woodford (1997). Rational asset pricing bubbles. Econometrica: Journal of the Econometric Society, 19-57.

Scherbina, A. (2013). Asset Price Bubbles: A Selective Survey. International Monetary Fund.

Shiller, R. J. (1981). Do stock prices move too much to be justified by subsequent changes in dividends? The American Economic Review 71(3), 421-436. 
Smith, M. H. and G. Smith (2006). Bubble, bubble, where's the housing bubble? Brookings Papers on Economic Activity 2006(1), 1-67.

Taipalus, K. (2006). A global house price bubble? Evaluation based on a new rent-price approach. Bank of Finland Research Discussion Papers, 29.

Taylor, J. B. (2007, December). Housing and monetary policy. Working Paper 13682, National Bureau of Economic Research.

West, K. D. (1987). A specification test for speculative bubbles. The Quarterly Journal of Economics 102(3), 553-580.

Wu, Y. (1995). Are there rational bubbles in foreign exchange markets? Evidence from an alternative test. Journal of International Money and Finance 14(1), 27-46.

Yiu, M. S., J. Yu, and L. Jin (2013). Detecting bubbles in Hong Kong residential property market. Journal of Asian Economics. 